\title{
Terpenes: Natural Products for Controlling Insects of Importance to Human Health-A Structure-Activity Relationship Study
}

\author{
José S. Dambolena, María P. Zunino, Jimena M. Herrera, Romina P. Pizzolitto, \\ Vanessa A. Areco, and Julio A. Zygadlo
}

Instituto Multidisciplinario de Biología Vegetal (IMBiV-CONICET), Cátedra de Química Orgánica, Universidad Nacional de Cordoba (FCEFyN), Avenida Vélez Sarsfield 1611, X5016GCA Córdoba, Argentina

Correspondence should be addressed to María P. Zunino; paula.zunino.254@unc.edu.ar

Received 27 April 2016; Revised 17 August 2016; Accepted 21 August 2016

Academic Editor: Zeljko Tomanovic

Copyright (C) 2016 José S. Dambolena et al. This is an open access article distributed under the Creative Commons Attribution License, which permits unrestricted use, distribution, and reproduction in any medium, provided the original work is properly cited.

\begin{abstract}
Many insects affect food production and human health, and in an attempt to control these insects the use of synthetic insecticides has become widespread. However, this has resulted in the development of resistance in these organisms, human diseases, contamination of food, and pollution of the environment. Plants natural products and essential oil components such as terpenes and phenylpropenes have been shown to have a significant potential for insect control. However, the molecular properties related to their insecticidal activity are not well understood. The purpose of this review is to provide an overview of the toxicity of terpene compounds against three insects of importance to human health: lice, cockroaches, and Triatominae bugs and to evaluate which molecular descriptors are important in the bioactivity of terpenes. For the insects studied, quantitative structure-activity relationship (QSAR) studies were performed in order to predict the insecticidal activity of terpene compounds. The obtained QSAR models indicated that the activity of these compounds depends on their ability to reach the targets and to interact with them. The QSAR analysis can be used to predict the bioactivities of other structurally related molecules. Our findings may provide an important contribution in the search for new compounds with insecticidal activity.
\end{abstract}

\section{Introduction}

As many insects affect food production and human health, synthetic insecticides have often been used to control insects. However, an inappropriate use of these insecticides is linked to the development of resistance in pests, human diseases, and contamination of both the food and the environment [14]. Consequently, the biological action of natural products with insecticidal activity is a very important alternative, which allows an environment-friendly management of pest insects without affecting people's health.

Plants produce a wide diversity of compounds involved in their chemical defense. Among these natural products, terpene compounds have been shown to have a significant potential for insect control [1-5]. However, little is known about the molecular properties related to their insecticidal activity.
The quantitative structure-activity relationship (QSAR) is a mathematical expression by which the chemical structure is quantitatively correlated with well-known processes such as biological activity or chemical reactivity. In general, bioactivity studies using pure compounds tend to use molecules of different structures. Thus, for example, alcohols, ketones, and phenols with acyclic, monocyclic, or bicyclic structures are usually evaluated together. Although an initial study of bioactivities using a large number of molecules may provide some guidance on the chemical families of highest activity, not all the existing molecules can always be used, owing to practical and economic reasons. The use of molecules with high chemical diversity also causes problems for a QSAR analysis, as it is difficult to achieve a good correlation between the different physicochemical characteristics and bioactivities tested. This situation leads 
us to select only certain molecules based on bibliographic information, causing an inherent limitation. Consequently, making an assessment using molecules of the same chemical family with small structural changes gives more appropriate information on the strength of these molecules as bioactive compounds than using a set of molecules that represent a large chemical diversity. Therefore, in our QSAR studies, a homologous series of compounds or derivatives of substances selected from bibliographic data were used, which reduced the variability of topological and electronic features that results from using a variety of structures and hinders the regression analysis when obtaining a predictive model. A QSAR study shows the connection between a set of predictor variables (chemicals) and the response variable (biological activity) of the chemicals. QSAR models create a relationship between chemical structures and biological activity in a data set of chemicals. However, as limited bibliographic information was obtained from the QSAR studies with pest insects, in the present study, we used the results of some investigations related to this issue. Furthermore, we performed QSAR models on the physicochemical descriptors of the terpene compounds and their insecticidal activities against three insects of importance to human health, namely, lice, cockroaches, and Triatominae bugs (vector of Chagas disease).

\section{Molecular Modelling, Calculation of Molecular Parameters, and Statistical Analysis}

The bioactivities of natural compounds were selected from bibliographic data, and the physicochemical, electronic, and topological descriptors of these molecules were used for the QSAR analysis.

The descriptors used for each molecule were octanol/water partition coefficient $(\log P)$, molar refractivity, molar volume, parachor, index of refraction, surface tension, density, polarizability, polar surface area ( $\mathrm{pH}$ 7.4), molecular surface area, and solvent-accessible surface area of all polar atoms, which were calculated using ChemAxon Soft (Cambridge Soft Corp.) [6]. Vapor pressure, boiling point, hydrogen bond donors, hydrogen bond receptors, vapor density, enthalpy of vaporization, and dipole were obtained by using ChemSpider 2014 [7].

A multiple linear regression analysis (MLR) was performed in order to examine the quantitative relationships between linear combinations of the dependent variable ( $\log (1 /$ bioactivity) or LN (inhibition\%)) with the predictor variables (structure and molecular properties). In the MLR equations, $N$ is the number of data points, $R$ is the correlation coefficient between observed values of the dependent variable and the values calculated from the equation, and $R^{2}$ is the square of the correlation coefficient and represents the goodness of fit. The obtained QSAR model was validated using the root mean square prediction error (RMSPE), obtained by cross validation leave-one-out procedure. Results with $P$ values $<0.05$ were considered to be significant.
All statistical analyses were performed using the InfoStat software Professional 2010 p [8].

\section{Lice}

Lice infestation or pediculosis is a global problem. Usually, the lice that infest humans are sucking lice that live in close association with the host and lay their eggs on hair shafts or in the seams of clothing [9]. Pediculus humanus humanus (Linnaeus 1758) and Pediculus humanus capitis (De Geer 1767) are two obligate ectoparasites which affect the body and head of the host, respectively, with Pediculus humanus appearing to be the vector of Rickettsia prowazeki and Borrelia recurrentis, two microorganisms of importance to human health [10-12]. The management of head lice infestation has a major disadvantage compared to the control of other insect pests, as the human hosts want the head lice to be completely eliminated [13]. However, the search to achieve total elimination and the use of inappropriate chemical controls have allowed head lice to develop resistance [14] to a significant number of pesticides such as lindane, DDT, carbaryl, malathion, and pyrethroids $[11,15,16]$. Consequently, the use of naturally occurring insecticidal compounds could be an attractive alternative to control head lice, including those which are resistant to pesticides [14]. Many scientific studies have proposed the use of various natural compounds, with essential oils having been shown to have different activities such as repellent, ovicidal, and adulticide properties in a variety of insect species, including head lice $[3,11,13$, 15-27]. Essential oils and terpenes have also been used in combination with conventional insecticides, and the results of these experiments have demonstrated an increase in the pediculicide properties of synthetic compounds $[15,28]$. Nevertheless, one problem in controlling head lice with essential oils is the variability present in their composition, which can be observed within a species because of environmental conditions (soil, moisture, nutrients, etc.), and it prevents a standard formulation being effective for the control of head lice. Thus, pure compounds of essential oils should be used in the control of body and head lice.

3.1. Terpenes against Adult Head Lice. Essential oils have shown different results as pediculicidal agents $[3,11,20,22$, 24-26, 28-33]. Among the components of essential oils, 1,8cineole, anisole, limonene, $\beta$-pinene, linalool, menthone, $\alpha$ pinene, pulegone, and myrcene have demonstrated fumigant activity $\left(\mathrm{KT}_{50}<53 \mathrm{~min}\right)$ whereas eugenol, borneol, menthol, isomenthol, anethole, camphor, carvone, menthyl acetate, linalyl acetate, thymol, p-cymene, $\gamma$-terpinene, $\alpha$-terpineol, and 4-terpineol had no effect $\left(\mathrm{KT}_{50}>60 \mathrm{~min}\right)[3,11,13,19$, 20]. Moreover, Gonzalez-Audino et al. [34] and Gallardo et al. [35] reported that citronellol and geraniol had the highest toxicity on adults for immersion and topical application methods, respectively.

It has been suggested that the mechanism of action of essential oil components could be due to competitive inhibition of the enzyme acetylcholinesterase (AChE, EC 3.1.1.7). Some researchers indicated that ketone compounds 
TABLE 1: Calculated molecular descriptors ${ }^{\mathrm{a}}$ for terpene and phenylpropene compounds used in QSAR analysis of the fumigant activity against head lice.

\begin{tabular}{lcccc}
\hline Compounds $^{\mathrm{b}}$ & MV & PSA & BP & HBA \\
\hline 1,8-Cineole & 167.1 & 9.23 & 177 & 2 \\
Anisole & 113.4 & 9.23 & 155 & 2 \\
Anethole & 154.4 & 9.23 & 237.5 & 2 \\
Eugenol & 156.2 & 29.46 & 252.5 & 4 \\
Thymol & 154.2 & 20.23 & 231.5 & 2 \\
Linalool & 179.6 & 19.62 & 199 & 2 \\
Benzyl alcohol & 103.2 & 20.23 & 205 & 2 \\
(+)-Borneol & 155.3 & 20.23 & 212.5 & 2 \\
Citronellol & 184.9 & 20.23 & 225 & 2 \\
Menthol & 175.5 & 20.23 & 216 & 2 \\
Isomenthol & 175.5 & 18.96 & 218.5 & 2 \\
Camphor & 154.8 & 17.59 & 204.5 & 1 \\
Carvone & 159.7 & 18.03 & 230.5 & 2 \\
Geraniol & 177.9 & 19.7 & 230 & 2 \\
Menthone & 175 & 17.07 & 209.5 & 2 \\
Pulegone & 164.8 & 17.07 & 221 & 2 \\
Limonene & 163.2 & 0 & 176 & 0 \\
$\alpha$-Pinene & 154.9 & 0 & 156 & 0 \\
$\beta$-Pinene & 153 & 0 & 165 & 0 \\
Myrcene & 177 & 18.85 & 167 & 0 \\
$\gamma$-Terpinene & 161.1 & 18.01 & 182 & 0 \\
\hline
\end{tabular}

${ }^{\mathrm{a}}$ The descriptors were calculated by ChemAxon and ChemSpider software.

${ }^{\mathrm{b}}$ The data on lice were obtained by Toloza [13].

augment the inhibitory effect on AChE because of the presence of the double bond of the carbonyl group [36, 37]. Picollo et al. [38] showed that two ketones, menthone and carvone, significantly inhibited AChE activity in head lice, but another study reported that carvone did not have a good fumigant activity against lice [11]. Other terpenes and phenylpropenes that have demonstrated inhibitory effects on AChE of head lice are 1,8-cineole and eugenol, while isomenthol and menthol were reported not to have any inhibitory activity [38].

The use of essential oils permits interaction with different targets simultaneously as a result of chemical diversity, although chemical diversity of an essential oil with a high bioactivity is difficult to reproduce. An artificial mixture of terpenes or phenylpropene has demonstrated a high activity and could have synergistic effects $[35,39]$, with linalyl acetate mixed with other terpenes showing a better synergistic effect on the inhibition of $\mathrm{AChE}$ activity than many isolated compounds.

We performed a multiple linear regression analysis to determine the mathematical function that could best predict the fumigant activity of some oxygenated terpenes, namely, 1,8-cineole, anisole, anethole, eugenol, thymol, linalool, benzyl alcohol, borneol, citronellol, menthol, isomenthol, camphor, carvone, geraniol, menthone, and pulegone, with the calculated molecular descriptors used in the analysis being shown in Table 1 . The obtained model was statistically significant $(P=0.0001)$, and it predicted $\mathrm{KT}_{50}\left(\mathrm{~min}^{-3}\right)$ based on four molecular properties, namely, boiling point (BP), polar surface area (PSA), molar volume (MV), and hydrogen bond acceptor (HBA):

$$
\begin{aligned}
& \log \left(\frac{1}{\mathrm{KT}_{50}}\right)= 0.23(\mathrm{HBA})+0.0023(\mathrm{MV})-0.01(\mathrm{BP}) \\
&-0.01(\mathrm{PSA})+2.77, \\
& N=16 ; R^{2}=0.96 ; \mathrm{RMSPE}=10.5 \% ; P<0.0001 .
\end{aligned}
$$

A second QSAR analysis was performed in order to include the terpene hydrocarbons limonene, $\alpha$-pinene, $\beta$-pinene, myrcene, and $\gamma$-terpinene in the model. The obtained model was statistically significant $(P=0.0001)$, and it predicted the toxicity $\left(\mathrm{KT}_{50}\right)$ of the terpenes (in (2)) based on boiling point (BP), polar surface area (PSA), and hydrogen bond acceptor (HBA). The incorporation of hydrocarbon compounds induced a decrease of model fit, suggesting that the use of homologous series reduces the variability features that hinder regression analysis. The resulting equation was of the following form:

$$
\begin{aligned}
& \log \left(\frac{1}{\mathrm{KT}_{50}}\right)= 0.01(\mathrm{BP})-0.01(\mathrm{PSA})+0.2(\mathrm{HBA}) \\
&+2.82 \\
& N=21 ; R^{2}=0.81 ; \mathrm{RMSPE}=7.3 \% ; P<0.0001 .
\end{aligned}
$$

The analysis of compounds of different chemical natures can cause a loss of fit of the QSAR model (in (2)) and therefore can lead to conflicting conclusions. For example, according to model 1 , oxygenated terpenes of lower boiling points should be more active, while, according to model 2, these should be less active. Also, the plot of calculated versus experimental $\log \left(1 / \mathrm{KT}_{50}\right)$ is shown in Figures 1 and 2, with HBA being an important descriptor in both formulas. Thus, an increase in the value of HBA represents a greater insecticidal activity. However, it is known that hydrocarbons have no HBA, and hence this descriptor in (2) would represent a dipole-dipole interaction between the hydrocarbons and target instead of HBA.

3.2. Ovicidal Effects. One way to control head lice infestation is by reducing the development of their eggs. Bibliographic information shows some components of essential oils having a high ovicidal activity, such as methyl salicylate, eugenol, linalool, terpinen-4-ol, carveol, geraniol, nerolidol, thymol, $\alpha$-terpineol, 1,8-cineole, linalool, carvone, anethole, anisole, $\alpha$-pinene, $\beta$-pinene, limonene, salicylaldehyde, benzaldehyde, cinnamaldehyde, and benzyl cinnamate [13, 29-31, 33]. However, other studies did not reveal any ovicidal activity in the following compounds: menthol, isomenthol, nonyl alcohol, benzyl alcohol, citronellol, geraniol, camphor, menthone, eugenol, thymol, terpinene and acetate esters of menthol and linalool, acetyleugenol, caryophyllene, humulene, isoeugenol, methyl eugenol, 1-R-terpineol, (E)-pinocarveol, 


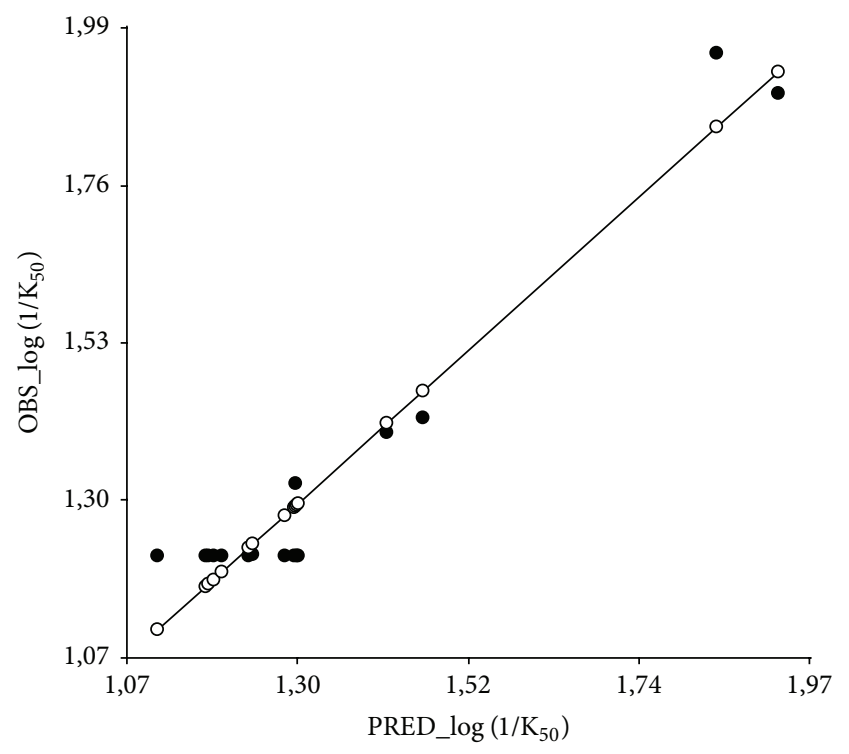

FIGURE 1: Multiple linear regression analysis (MLR) calculated to examine quantitative relationships between linear combinations of the dependent variable $\log \left(1 / \mathrm{KT}_{50}\right)$ and the predictor variables (structure and molecular properties). Plot of calculated versus experimental $\log \left(1 / \mathrm{KT}_{50}\right)$ of fumigant activity of oxygenated terpenes against lice.

salicylaldehyde, benzaldehyde, cinnamaldehyde, benzyl cinnamate, benzyl alcohol, limonene, $\alpha$-pinene, $\beta$-pinene, $\gamma$ terpinene, $\alpha$-terpinene, 1,8-cineole, and cinnamyl acetate [29-31]. Moreover, from bibliography, it can be seen that there are conflicting results regarding the efficiency of essential oil components for lice control, possibly related to the different techniques used for evaluating the bioassays. It has also been suggested that pediculicidal activity developed by the components of essential oils also depends on the Pediculus species [13, 29-31].

In this section, the order of toxicity of 20 natural components of essential oils to ovicidal activity against Pediculus humanus capitis is examined using data previously reported by Toloza [13]. These results show that the ether terpenes 1,8-cineole, anisole, and anethole and also the hydrocarbon terpenes limonene, $\alpha$-pinene, $\beta$-pinene, and $\gamma$-terpinene were the most active compounds evaluated. A QSAR analysis was performed in order to determine the mathematical function that best fitted or predicted the activity of alcohol and the ketone terpenes. However, the most active terpenes (ether and hydrocarbon) were not included in this QSAR analysis, because they increased the chemical diversity and thereby influenced the fit obtained in the model. On the other hand, the ether and hydrocarbon terpenes were not sufficient to perform a QSAR analysis.

The calculated molecular descriptors used in the analysis are shown in Table 2. The model obtained using alcohols and ketones is given by the following expression:

$$
\begin{aligned}
& \mathrm{LN}(\text { Inhibition\% })=-0.011(\mathrm{BP})+26.10, \\
& \quad N=9 ; R^{2}=0.84 ; \mathrm{RMSPE}=15.4 \% ; \quad P=0.0013 .
\end{aligned}
$$

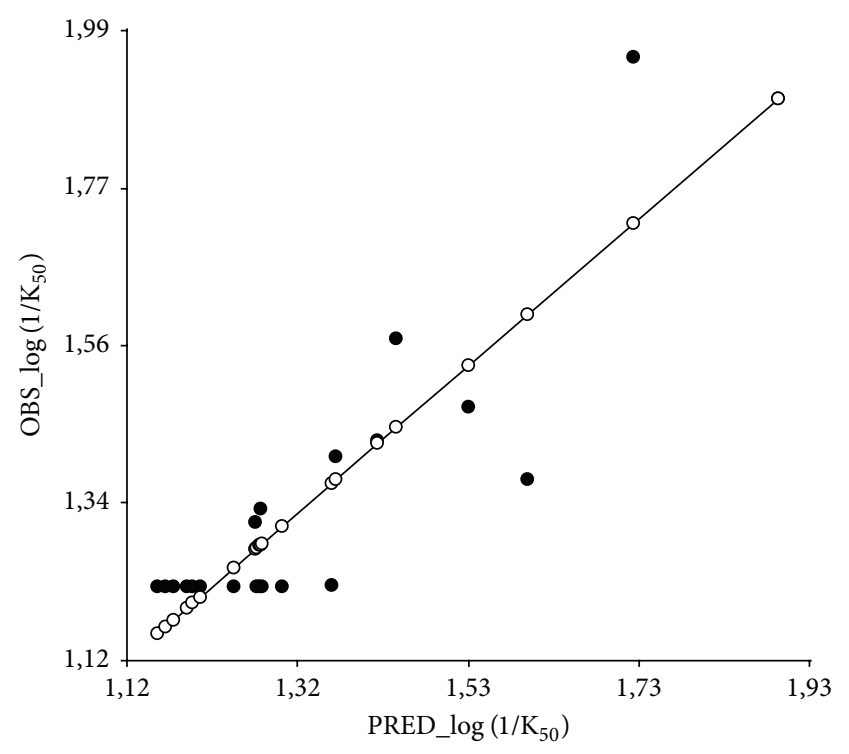

FIGURE 2: Multiple linear regression analysis (MLR) calculated to examine quantitative relationships between linear combinations of the dependent variable $\log \left(1 / \mathrm{KT}_{50}\right)$ and the predictor variables (structure and molecular properties). Plot of calculated versus experimental $\log \left(1 / \mathrm{KT}_{50}\right)$ of fumigant activity of oxygenated and hydrocarbon terpenes against lice.

TABLE 2: Calculated molecular descriptors ${ }^{\mathrm{a}}$ for alcohol and ketone compounds used in QSAR analysis of the ovicidal activity against Pediculus humanus capitis.

\begin{tabular}{lc}
\hline Compounds $^{\mathrm{b}}$ & $\mathrm{BP}$ \\
\hline Linalool & 198.5 \\
Benzyl alcohol & 204.7 \\
Menthol & 215.3 \\
Isomenthol & 215.4 \\
Geraniol & 229.49 \\
Menthone & 205 \\
Camphor & 207.4 \\
Nonyl alcohol & 211.6 \\
Citronellol & 224.5 \\
\hline
\end{tabular}

${ }^{\mathrm{a}}$ The descriptors were calculated by ChemAxon and ChemSpider software.

${ }^{\mathrm{b}}$ The data on lice were obtained by Toloza [13].

The negative coefficients of BP indicate that an increase in this descriptor led to a decrease in ovicidal toxicity, with this QSAR model showing a good correlation between the estimated and experimentally measured toxicity parameters for the tested monoterpenes and phenylpropenes. This result is in agreement with the high activity of ethers and hydrocarbons terpenes reported by Toloza [13], because these are the most volatile compounds evaluated in the cited work. A plot of the calculated versus experimental LN (inhibition\%) is shown in Figure 3. Developing these types of relationships may facilitate the design of more effective ovicidal components and provide an insight into the structural properties that are responsible for their toxicities. 


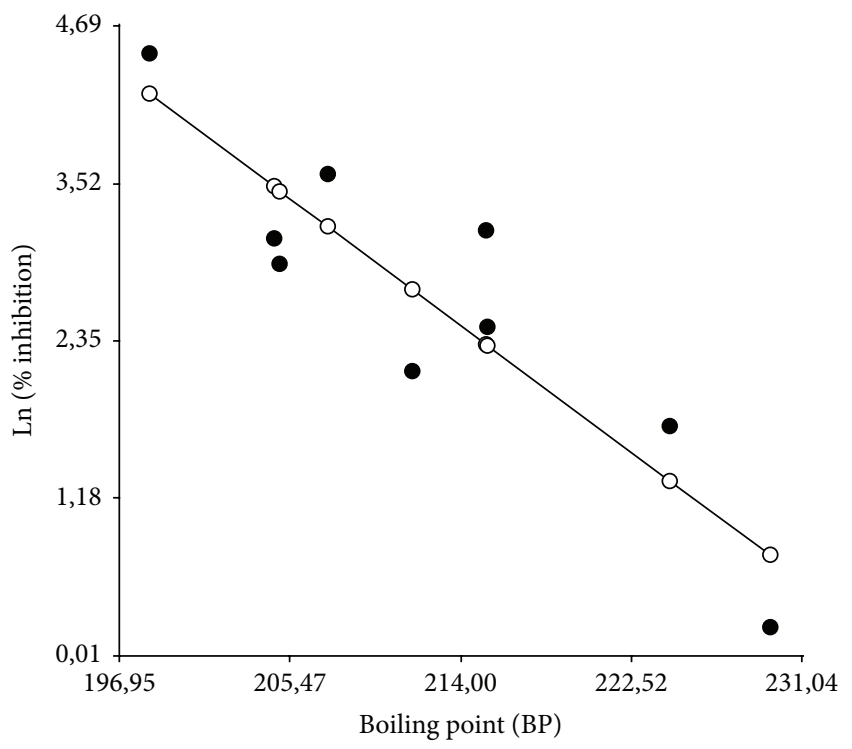

FIGURE 3: Multiple linear regression analysis (MLR) calculated to examine quantitative relationships between linear combinations of the dependent variable LN (Inhibition\%) and the predictor variables (structure and molecular properties). Plot of calculated versus experimental LN (Inhibition\%) of ovicidal activity of alcohol and ketone terpenes against lice.

3.3. Repellent. Repellency can help describe the behavioral effects that alter the perception of the peripheral nervous system (PNS), which leads to the insect neither biting nor sucking and causes them to move away from their food source [40]. Thus, repellency is a strategy to prevent reinfection of host by an ectoparasite but does not result in the death of the insect. Essential oils have developed a very important role as natural repellent agents $[13,15,41]$, with the results of the previously reported studies showing that benzyl alcohol was the most effective compound with a repellent index of $57.74 \%$, followed by (-)-menthol, menthone, and (+)-menthol, with RI values of $53.56,39.23$, and $36.45 \%$, respectively.

Toloza et al. [11] were the first to report on the potential of acyclic lactones as head lice repellents, with the repellent activity of these lactones ranging from 60 to $76 \%$ (equivalent to piperonal repellent) and $\delta$-dodecalactone being the most active (76.68\%). In addition, the lactone compounds were more active than the terpene ones. In fact, the $\delta$ - and $\gamma$ lactones are common components in the aroma of coconut oil.

\section{Cockroaches}

The term "cockroaches" covers a large number of species which have a worldwide distribution, with these insects being considered to be excellent transporters of pathogenic and allergic substances of faecal origin [42, 44]. However, as occurs in the control of other pests, the frequent use of synthetic insecticides has also generated resistance in cockroaches. Moreover, the enormous potential toxicity of synthetic insecticides has led to their use being restricted in establishments where food is prepared, such as in the hospitals [42]. As mentioned above, the new phytoinsecticides can be applied in both open and closed places, in the same way as synthetic insecticides, with essential oils and their components being considered minimum risk pesticides [45].

Several studies have reported insecticidal activities of terpenes against cockroaches. An important aspect in the evaluation of phenylpropene or terpenes as insecticides against cockroaches is the sex of the insect, and the results of different investigations have shown the necessity of higher doses of the insecticide for females [46-49]. As cockroach females have a higher body lipid concentration than males, this situation may be generating a differential effect on the actions of essential oils. Also, males are more sensitive to the insecticidal action of terpenes. Thus, the higher concentration of lipids in the female body might be trapping the terpenes and thereby avoiding their insecticidal action [47]. However, there are other factors that differentially affect males and females in insecticidal bioassays. For example, thymol, transcinnamaldehyde, 1,8-cineole, and menthone terpenes have been demonstrated to have different sensitivities between males and females [46, 48].

The experimental results reported by Jang et al. [42] were now used to perform a quantitative structure-activity analysis, with the molecular descriptors used in the QSAR studies being listed in Tables 3, 4, and 5 .

4.1. Contact Toxicity Bioassay. In the contact assay, the values of $\mathrm{LC}_{50}$ ( $24 \mathrm{~h}$ exposure) in female B. germanica revealed the adulticidal activity of pulegone $\left(0.06 \mathrm{mg} / \mathrm{cm}^{2}\right)$, camphor $\left(0.07 \mathrm{mg} / \mathrm{cm}^{2}\right)$, and verbenone $\left(0.07 \mathrm{mg} / \mathrm{cm}^{2}\right)$, with similar results for camphor and pinene isomers having been reported by Jung et al. [50]. In contrast, linalool, terpineol, thymol, perillaldehyde, 1,8-cineole, and thujone showed a range of adulticidal activities between 0.09 and $0.18 \mathrm{mg} / \mathrm{cm}^{2}$ [42]. The insecticidal activity of pulegone may also be explained by its interaction with the octopamine receptor. Pulegone, pcymene, trans-anethole, vanillin, and isoeugenol are terpenes and phenylpropenes which exert strong octopaminergic receptor antagonist activity at concentrations of $2 \mathrm{nmol} / \mathrm{mL}$ [51]. The lower insecticidal activity of linalool and terpineol could be due to their lack of interaction with the octopamine receptor [42]. In the case of terpineol, the binding activity of octopamine receptors was blocked with an approximate $\mathrm{IC}_{50}$ value of $9 \mathrm{nmol} / \mathrm{mL}$ [51].

Yeom et al. [49] showed that eugenol, isoeugenol, methyl eugenol, terpinen-4-ol, carveol, cuminaldehyde, (S)-(+)carvone, trans-anethole, thymol, and p-cymene had a strong activity at $1 \mathrm{mg} /$ adult in a topical application bioassay.

Two QSAR models were utilized for evaluating the contact toxicity assay:

(i) "Alcohols and phenols" (thymol, $\alpha$-terpineol, linalool, verbenol, menthol, carvacrol, (-) carveol, terpinen-4-ol, borneol, citronellol, geraniol, and cinnamyl alcohol)

(ii) "Aldehydes and ketones" (pulegone, camphor, verbenone, $\alpha$-thujone, 1,8-cineole, perillaldehyde, cinnamaldehyde, menthone, carvone, and citronellal) 
TABLE 3: Calculated molecular descriptors ${ }^{\mathrm{a}}$ for alcohol and phenol compounds used in QSAR analysis of the insecticidal activity against cockroach species.

\begin{tabular}{lcccccccc}
\hline Compounds $^{\mathrm{b}}$ & Rings & pka & MV & Parachor & RI & ASA & ASAH & ASAP \\
\hline Thymol & 1 & 10.59 & 154 & 374.9 & 1.52 & 356.3 & 329.7 & 26.6 \\
$\alpha$-Terpineol & 1 & 19.4 & 164.9 & 396 & 1.48 & 335.6 & 318.4 & 17.2 \\
Linalool & 0 & 18.46 & 179.6 & 414.2 & 1.46 & 378.4 & 358.1 \\
Verbenol & 2 & 18.59 & 151.8 & 362.5 & 1.51 & 290 & 266.4 & 23.2 \\
Menthol & 1 & 19.55 & 175.5 & 409.8 & 1.46 & 336.9 & 313.8 \\
Carvacrol & 1 & 10.42 & 154.2 & 374 & 1.52 & 364 & 328.9 & 23.1 \\
(-)-Carveol & 1 & 18.21 & 160.2 & 383.1 & 1.5 & 313.8 & 289 & 24.3 \\
Terpinen-4-ol & 1 & 20 & 165.2 & 396 & 1.48 & 317.5 & 301 \\
Borneol & 2 & 19.6 & 155.3 & 381.2 & 1.5 & 273.6 & 250.7 & 16.5 \\
Citronellol & 0 & 17.11 & 184.9 & 427.5 & 1.45 & 419.1 & 378.6 & 22.9 \\
Geraniol & 0 & 16.33 & 177 & 413.5 & 1.47 & 411.6 & 367.5 & 40.5 \\
Cinnamyl alcohol & 1 & 15.62 & 127.9 & 326.9 & 1.56 & 328.8 & 284.1 & 44.7 \\
\hline
\end{tabular}

${ }^{\mathrm{a}}$ The descriptors were calculated by ChemAxon and ChemSpider software.

${ }^{\mathrm{b}}$ The data on cockroach species were obtained by Jang et al. [42].

TABLE 4: Calculated molecular descriptors ${ }^{\mathrm{a}}$ for aldehyde and ketone compounds used in QSAR analysis of the insecticidal activity against cockroach.

\begin{tabular}{|c|c|c|c|c|c|c|c|c|c|}
\hline Compounds $^{\mathrm{b}}$ & MV & Parachor & RI & ST & ASA & ASA+ & ASA- & $\mathrm{Vp}$ & $\mathrm{BP}$ \\
\hline Pulegone & 164.8 & 384.2 & 1.47 & 29.5 & 347 & 249.8 & 97.2 & 0.09 & 224 \\
\hline Camphor & 154.8 & 367.1 & 1.49 & 31.5 & 277.6 & 212 & 65.6 & 0.23 & 207.4 \\
\hline Verbenone & 151.4 & 352.7 & 1.49 & 29.4 & 293.7 & 210.5 & 83.3 & 0.08 & 227.5 \\
\hline$\alpha$-Thujone & 150.8 & 366.8 & 1.5 & 34.9 & 318 & 236.3 & 81.7 & 0.32 & 200.5 \\
\hline 1,8-Cineole & 167.1 & 399.1 & 1.46 & 32.4 & 307.7 & 242.4 & 65.3 & 1.65 & 174 \\
\hline Perillaldehyde & 149.8 & 377.1 & 1.54 & 40.1 & 317.1 & 237.2 & 79.9 & 0.04 & 238 \\
\hline Cinnamaldehyde & 127.7 & 319.1 & 1.58 & 38.9 & 299.2 & 210.3 & 88.9 & 0.03 & 246.8 \\
\hline Menthone & 175 & 400 & 1.44 & 27.2 & 346.6 & 262.6 & 84.1 & 0.26 & 205 \\
\hline Carvone & 159.7 & 373.3 & 1.48 & 29.8 & 302.7 & 233.3 & 69.3 & 0.07 & 230.5 \\
\hline Citronellal & 184.7 & 419.6 & 1.44 & 26.6 & 401.5 & 282.3 & 119.1 & 0.21 & 208.4 \\
\hline
\end{tabular}

${ }^{\mathrm{a}}$ The descriptors were calculated by ChemAxon and ChemSpider software.

${ }^{b}$ The data on cockroach species were obtained by Jang et al. [42].

The model obtained for group (i) is given by the following expression:

$$
\begin{aligned}
\log \left(\frac{1}{\mathrm{LC}_{50}}\right)= & -0.09(\text { ASA P })-0.81 \text { (rings) } \\
& -0.08 \text { (Parachor) }-46.67(\mathrm{RI}) \\
& -0.17(\mathrm{Pka})+108.7 \\
N=12 ; R^{2}= & 0.98 ; \text { RMSPE }=17.6 \% ; P=0.002 ;
\end{aligned}
$$

and the model obtained for group (ii) is given by the following expression:

$$
\begin{aligned}
& \log \left(\frac{1}{\mathrm{LC}_{50}}\right)= 0.25(\mathrm{ST})+0.02(\mathrm{ASA})-52.29(\mathrm{RI}) \\
&-2.33(\mathrm{VP})-0.05(\mathrm{ASA}+) \\
&-0.05(\mathrm{MV})+85.74 \\
& N=10 ; R^{2}=0.97 ; \mathrm{RMSPE}=8.2 \% ; P=0.0028
\end{aligned}
$$

As the analysis of monoterpene hydrocarbons did not adjust properly to the quantitative structure-activity analysis, this QSAR model was not reported. The plots of calculated versus experimental $\log \left(1 / \mathrm{LC}_{50}\right)$ are shown in Figures 4 and 5.

Equations (4) and (5) revealed that the index of the refraction or refractive index (RI) of the alcohol-phenol and aldehyde and ketone compounds negatively influences the lethal concentration $50\left(\mathrm{LC}_{50}\right)$, with the polarizability of the molecule being related to RI. In contrast, in (5), a rise in the vapor pressure (VP) of terpenes elevates the lethal concentration $50\left(\mathrm{LC}_{50}\right)$.

4.2. Fumigant Toxicity Bioassay. The results published in several scientific studies have shown that the presence of a carbonyl group in the terpene is important, which can act as an acceptor of hydrogen bonding. This may permit the terpene to interact with water molecules on the surface of the insect respiratory system (tracheoles) and consequently provides a better lead towards the target site $[42,52]$. When evaluating the terpenes as fumigants, a mechanism of action 


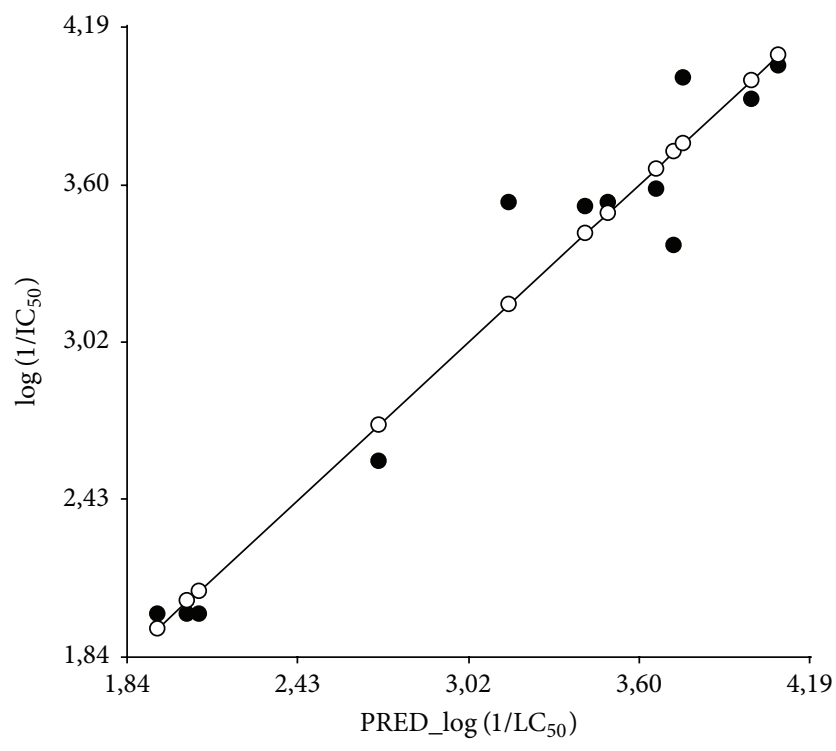

FIGURE 4: Multiple linear regression analysis (MLR) calculated to examine quantitative relationships between linear combinations of the dependent variable $\log \left(1 / \mathrm{LC}_{50}\right)$ and the predictor variables (structure and molecular properties). Plot of calculated versus experimental $\log \left(1 / \mathrm{LC}_{50}\right)$ of repellent activity of alcohol and phenol compounds against cockroaches.

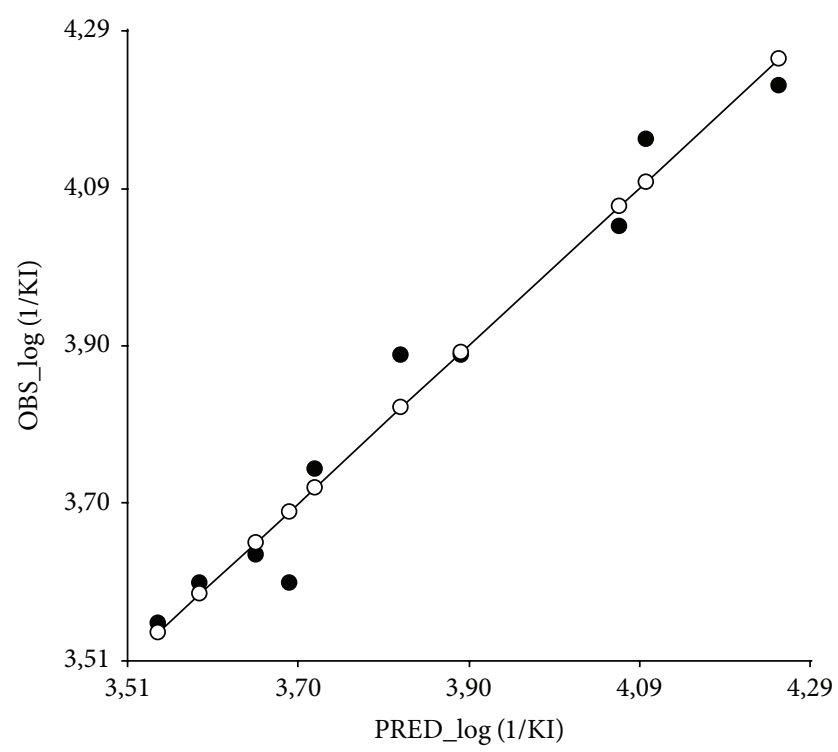

FIGURE 5: Multiple linear regression analysis (MLR) calculated to examine quantitative relationships between linear combinations of the dependent variable $\log \left(1 / \mathrm{LC}_{50}\right)$ and the predictor variables (structure and molecular properties). Plot of calculated versus experimental $\log \left(1 / \mathrm{LC}_{50}\right)$ of repellent activity of aldehyde and ketone compounds against cockroaches.

similar to the carbonyl group can be proposed for ether such as 1,8 -cineole [46].

The interaction of carbonyl groups of terpenes with the GABA receptor may be related to the fast knockdown of insects as a result of their interaction with the GABA receptors present in the insect neuromuscular junctions [53].
TABLE 5: Calculated molecular descriptors ${ }^{\mathrm{a}}$ for hydrocarbon compounds used in QSAR analysis of the fumigant efficacy against cockroach.

\begin{tabular}{lccc}
\hline Compounds $^{\mathrm{b}}$ & Rings & MV & $\log P$ \\
\hline$\alpha$-Phellandrene & 1 & 163.135 & 3.21 \\
2-Carene & 2 & 154.905 & 2.8 \\
$\gamma$-Terpinene & 1 & 161.128 & 3.16 \\
Camphene & 2 & 153.074 & 2.86 \\
$\beta$-Pinene & 2 & 153.074 & 2.86 \\
3-Carene & 2 & 154.905 & 2.8 \\
Limonene & 1 & 163.264 & 3.22 \\
$\alpha$-Terpinene & 1 & 161.128 & 3.16 \\
$\alpha$-Pinene & 2 & 154.905 & 2.8 \\
Myrcene & 0 & 177.007 & 3.54 \\
\hline
\end{tabular}

${ }^{\mathrm{a}}$ The descriptors were calculated by ChemAxon and ChemSpider software.

${ }^{b}$ The data on cockroach species were obtained by Jang et al. [42].

In contrast, thujone does not have a similar activity to other ketones, due to the presence of a cyclopropane in its structure, according to Tong and Coats [54].

Zhu et al. [55] reported that (Z)-ascaridole, isoascaridole, and p-cymene possessed fumigant toxicity against male German cockroaches. Other monoterpenes with observed fumigant activity include terpinolene, $\alpha$-terpinene, terpinen-4$\mathrm{ol}$, (S)-(+)-carvone, 1,8-cineole, trans-dihydrocarvone, cuminaldehyde, trans-anethole, p-cymene, and $\gamma$-terpinene [49, 56]. In addition, fumigant activity against $B$. germanica has been reported with carvacrol [57, 58], (E)-anethole [59], and thymol [42], with derivatives of the biosynthetic pathway of shikimic acid, such as isosafrole and safrole, having shown adulticidal activity against the female Periplaneta americana (L.) [60].

The QSAR studies for fumigant toxicity assay were represented by three models:

(i) "Alcohols and phenols" (thymol, $\alpha$-terpineol, linalool, verbenol, menthol, carvacrol, (-)-carveol, terpinen-4-ol, borneol, citronellol, geraniol, and cinnamyl alcohol)

(ii) "Aldehydes and ketones" (pulegone, camphor, verbenone, $\alpha$-thujone, 1,8-cineole, perillaldehyde, cinnamaldehyde, menthone, carvone, and citronellal)

(iii) "Hydrocarbons" ( $\alpha$-phellandrene, 2-carene, $\gamma$ terpinene, camphene, $\beta$-pinene, 3-carene, limonene, $\alpha$-terpinene, $\alpha$-pinene, and myrcene)

The algorithm for models (i), (ii), and (iii) is expressed in (6), (7), and (8), respectively:

$$
\begin{aligned}
\log \left(\frac{1}{\mathrm{LD}_{50}}\right)= & 0.10(\text { ASA } \mathrm{H})-0.08(\text { ASA }) \\
& -0.03(\mathrm{MV})+5.15
\end{aligned}
$$

$$
N=12 ; R^{2}=0.95 ; \text { RMSPE }=8.6 \% ; P<0.0001 \text {, }
$$




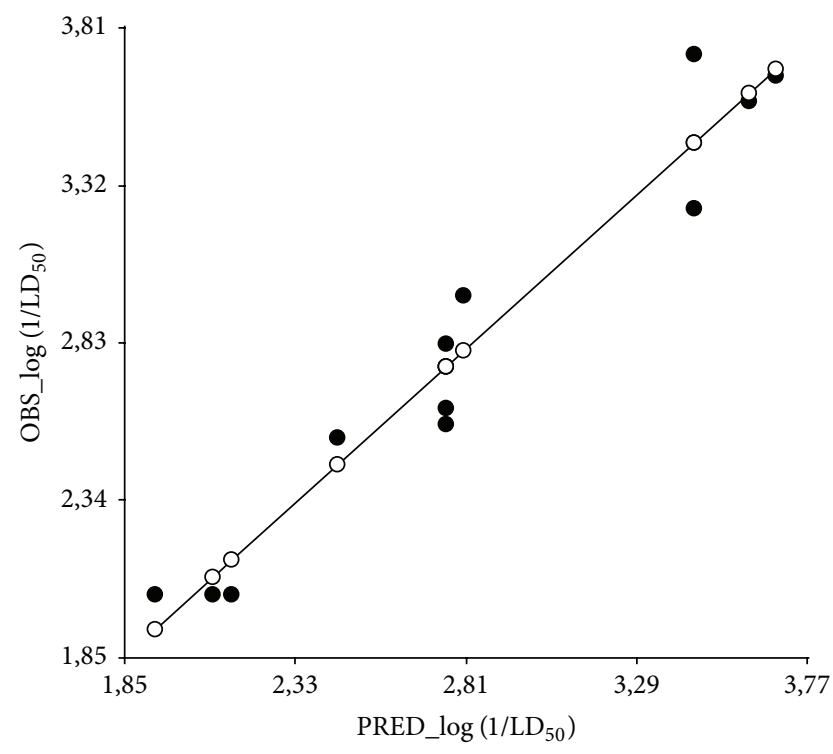

FIGURE 6: Multiple linear regression analysis (MLR) calculated to examine quantitative relationships between linear combinations of the dependent variable $\log \left(1 / \mathrm{LD}_{50}\right)$ and the predictor variables (structure and molecular properties). Plot of calculated versus experimental $\log \left(1 / \mathrm{LD}_{50}\right)$ of insecticidal activity of alcohol and phenol compounds against cockroaches.

$$
\begin{aligned}
\log \left(\frac{1}{\mathrm{LD}_{50}}\right)= & 0.02(\mathrm{BP})+0.01(\mathrm{ASA}-)-0.27(\mathrm{Pi} E) \\
& -0.02(\text { Parachor })+4.43, \\
N=10 ; R^{2}=0.97 ; \mathrm{RMSPE}=9.1 \% ; P=0.0006, & \\
\log \left(\frac{1}{\mathrm{LD}_{50}}\right)= & -3,15(\log P)-2.36(\text { rings }) \\
& -0.09(\mathrm{MV})+31.28
\end{aligned}
$$

$$
N=10 ; R^{2}=0.89 ; \quad \mathrm{RMSPE}=6.3 \% ; P=0.0029 \text {. }
$$

The plot of calculated versus experimental $\log \left(1 / \mathrm{LD}_{50}\right)$ is shown in Figures 6, 7, and 8. The regression model (in (6)) suggests that the insecticidal activity of the alcohol and phenolic compounds increases with a rise in the solventaccessible surface area for all hydrophobic atoms (ASA $H)$. In contrast, in (8), this increases for the hydrocarbon compounds with a rise in the logarithm of the octanol/water partition coefficient $(\log P)$.

In (7), the Pi energy ( $\mathrm{Pi} E$ ) of the ketone and aldehyde terpenes influences the insecticidal activity. The total Pi energy was calculated by the Huckel method and revealed a dissimilar charge distribution, which could result in a noncovalent interaction between aromatic amino acids of the proteins (e.g., AChE) and the organic compounds.

There has been much speculation about the structural relationship of terpenes and their bioactivity against cockroaches. Tortora et al. [61] argue that the degree of saturation of a compound may affect the detoxification because of which unsaturated terpenes may not be ordered in compact form,

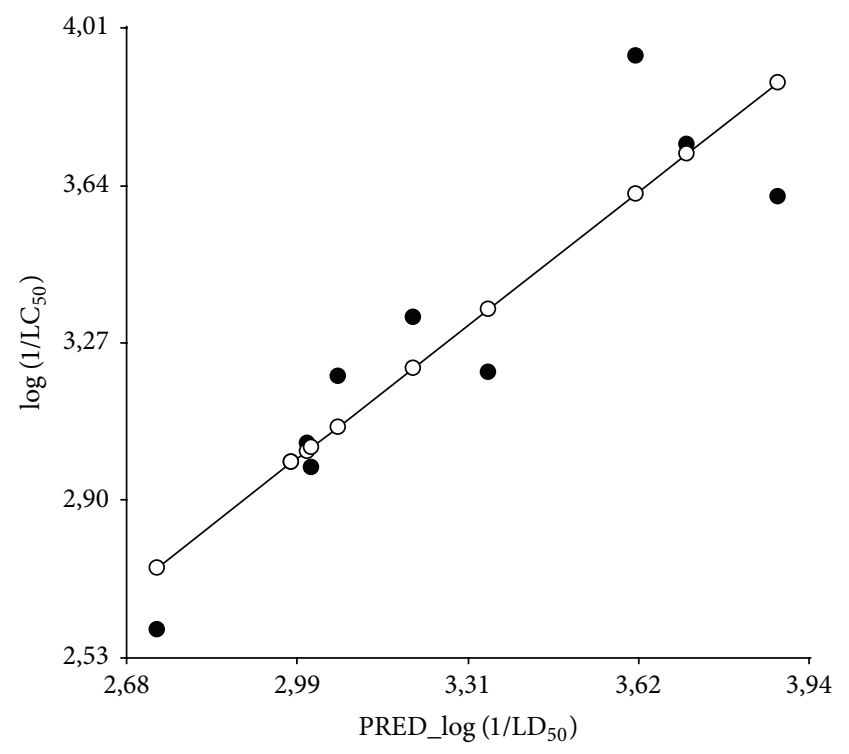

FIGURE 7: Multiple linear regression analysis (MLR) calculated to examine quantitative relationships between linear combinations of the dependent variable $\log \left(1 / \mathrm{LD}_{50}\right)$ and the predictor variables (structure and molecular properties). Plot of calculated versus experimental $\log \left(1 / \mathrm{LD}_{50}\right)$ of insecticidal activity of aldehyde and ketone compounds against cockroaches.

as the case of the saturated compounds, and consequently be more easily degraded. Steric aspects may also increase the solubility in the circulatory system of insects, allowing a more rapid excretion [42]. In fact, $\log P$ values of different terpenes have been interpreted in the light of their bioactivity in different ways. Matsumura [62] and Yu [47] found that high values of $\log P$ could enhance cuticular penetration and therefore favor insecticidal activity. However, monoterpene hydrocarbons with high $\log P$ values are less bioactive than those with lower ones [42]. Moreover, cuticles with a high content of lipid compounds can act as a trap for lipophilic substances and thus inhibit their traffic to the target site [47], implying that a positive relationship is not always found between lipophilicity and insecticidal activity $[46,48]$.

\section{Triatominae Bugs (Vector of Chagas Disease)}

Chagas disease is among the most important parasitic diseases of the southern region of America. It is caused by a protozoan parasite (Trypanosoma cruzi, Kinetoplastida, Trypanosomatidae) and can result at first in cardiological dysfunction and even lead to the patient's death [63]. The main vectors of the protozoan parasite are the hematophagous bugs Rhodnius prolixus (Stål, 1859), Rhodnius neglectus (Lent, 1954), and Triatoma infestans (Klug, 1834) (Hemiptera, Reduviidae, and Triatominae) $[64,65]$, which live in the inside and the surrounding areas of rural households. In Argentina, Bolivia, and Peru, the disease has been controlled since 1950 through elimination of the vector using synthetic insecticides [66]. Health agencies have used different strategies for the 


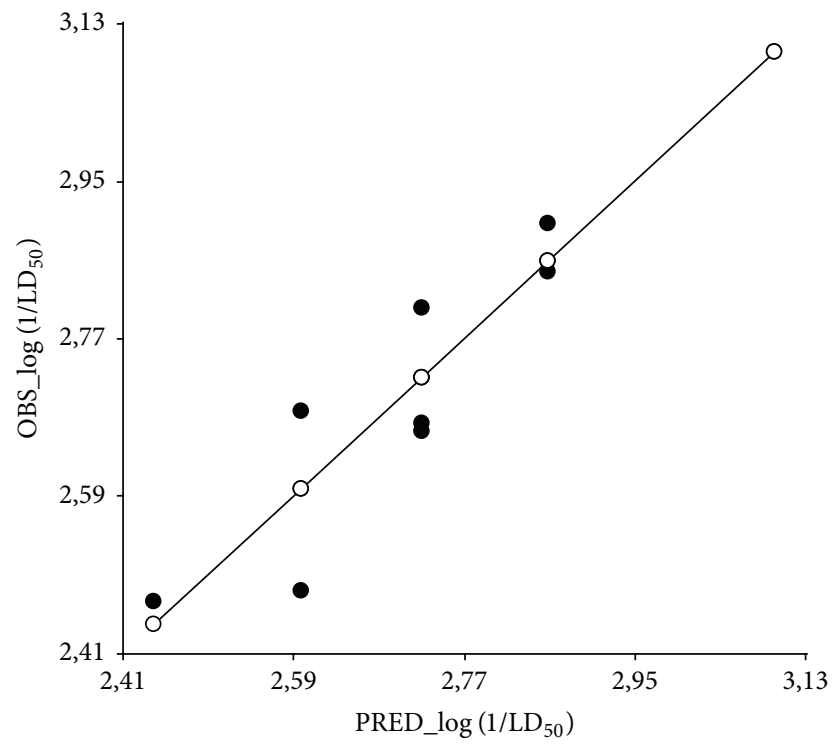

FIGURE 8: Multiple linear regression analysis (MLR) calculated to examine quantitative relationships between linear combinations of the dependent variable $\log \left(1 / \mathrm{LD}_{50}\right)$ and the predictor variables (structure and molecular properties). Plot of calculated versus experimental $\log \left(1 / \mathrm{LD}_{50}\right)$ of insecticidal activity of hydrocarbon compounds against cockroaches.

application of synthetic insecticides in rural households, with the most common method being the spraying technique, but painted surfaces with synthetic pesticides have also shown encouraging results $[67,68]$. However, there are recent studies indicating the development of resistance by $T$. infestans $[4,69,70]$. An alternative to synthetic insecticides is the use of aliphatic alcohols, which have been demonstrated to help control mosquitoes and lice. When synthetic pyrethroids are used together with alcohols, synergistic effects have been observed, and it has been speculated that the alcohol may be affecting the cuticle of the exoskeleton of the insects and thereby facilitating the entry of the insecticides [71]. The cuticular surface is covered by a thin layer of lipids (mainly hydrocarbons, wax esters, and fatty alcohols) and with free or esterified fatty acids. These lipids play a major role in preventing lethal desiccation by altering the absorption of chemicals and microorganism penetration, and they also participate in chemical communication events [72-74]. Some fatty acids, by being part of the epicuticular waxes in T. infestans, have a strong action of regrouping (e.g., hexacosanoic acid) [75].

Essential oils are an alternative to synthetic pesticides for controlling blood sucking bugs [43, 76-78], with Hedeoma mandoniana and Minthostachys andina having been used as insecticides on the bugs Rhodnius neglectus and Triatoma infestans, and topical application revealing an insecticidal activity of $33 \%$ and $50 \%$ for $H$. mandoniana and $M$. andina, respectively. However, the evaluation of these essential oils as a fumigant produced different results, with $H$. mandoniana oil combined with $25.5 \%$ menthone and $33 \%$ isomenthone showing a mortality between 30 and 50\% for the bugs, while $M$. andina with pulegone as the main component (44.6\%) had no effect. Aliphatic alcohols appear to affect the
TABLE 6: Calculated molecular descriptors ${ }^{\text {a }}$ for compounds used in QSAR analysis of the insecticidal activity on triatominae nymphs.

\begin{tabular}{lccccc}
\hline Compounds $^{\mathrm{b}}$ & ST & ASA & ASA+ & ASA- & BP \\
\hline Menthone & 27.2 & 346.6 & 262.6 & 84.1 & 209 \\
Isomenthol & 29.7 & 293 & 228.6 & 64.3 & 218 \\
Piperitone & 28.9 & 335.2 & 244.8 & 90.4 & 234 \\
Linalool & 28.2 & 378.4 & 288.1 & 90.2 & 199 \\
Pulegone & 29.5 & 347 & 249.8 & 97.2 & 221 \\
1,8-Cineole & 32.4 & 307.7 & 242.4 & 65.3 & 176 \\
Trans-anethole & 31.8 & 389.6 & 299.6 & 89.8 & 237.5 \\
Nerolidol & 29.6 & 493 & 381.1 & 111.9 & 276 \\
\hline
\end{tabular}

${ }^{a}$ The descriptors were calculated by ChemAxon and ChemSpider software.

${ }^{\mathrm{b}}$ The data were obtained by Laurent et al. [43].

cuticle of insects, thereby favoring the insecticidal action of some synthetic compounds. In addition, terpenes also affect components of the epicuticular waxes of insects, which could be a mechanism of pesticidal activity [79]. Repellent and ovicidal activities were also observed for different extracts from Schinus molle [80], and Eucalyptus urograndis essential oil had high insecticidal and repellent activities for $R$. neglectus nymphs $[76,77]$.

DEET (N,N-diethyl-3-methylbenzamide) is a synthetic compound that is used as repellent against mosquitoes and other Diptera, with the repellency of DEET on the bug vectors of Chagas disease having been tested by other authors [78, 81, 82]. As the antennae olfactory receptors of mosquitoes and bugs have been postulated as a possible site of action of DEET $[82,83]$, essential oil components could also have the same target.

We performed a quantitative analysis of the structureactivity relationship based on the work of Laurent et al. [43]. The oxygenated compounds menthol and alpha- and betathujone were omitted in the QSAR analysis because their larvicidal toxicity values were not determined in the cited reference, at the evaluated concentrations. These authors provided information about the menthol and thujone larvicidal toxicities as $>$ to $2 \mathrm{mg} / \mathrm{cm}^{2}$. The inaccuracy of this determination induced a decrease of model fit. The calculated molecular descriptors used in this analysis are shown in Table 6, and the plot of calculated versus experimental $\log \left(1 / \mathrm{LD}_{50}\right)$ is shown in Figure 9. The model obtained using a contact toxicity bioassay of terpenes on nymphs is given by the following expression:

$$
\begin{aligned}
& \log \left(\frac{1}{\mathrm{LD}_{50}}\right)= 3.24(\mathrm{ASA})+0.0049(\mathrm{BP})-0.05(\mathrm{ST}) \\
&-3.25(\mathrm{ASA}-)-3.24(\mathrm{ASA}+)+4.65, \\
& N=8 ; R^{2}=0.99 ; \mathrm{RMSPE}=7.8 \% ; P=0.0006 .
\end{aligned}
$$

This regression model (in (9)) suggests that the insecticidal activity of the alcohol and ketone compounds is influenced by the solvent-accessible surface areas. 


\section{Potential Targets: Mode of Action of Essential Oil Components}

Many insects have developed resistance to several classes of insecticides, which has created the need to search for and/or develop new effective pesticides to control them at any stage (egg, larvae, or adults). Resistance to insecticides may be defined as "a heritable change in the sensitivity of a pest population that is reflected in the repeated failure of a product to achieve the expected level of control when used according to the label recommendation for that pest species" [84]. Although the sites of action of synthetic pesticides are the most diverse, like action on the nervous system (AChE, gamma-aminobutyrate (Gaba), octopaminergic receptor, and sodium channel modulators), effects on the cuticle, growth regulators, and so forth [84], little is known about the sites of action of terpenes, despite pesticidal activity having been extensively studied.

The detoxification of aromatic structures is relatively more difficult than aliphatic ones and involves a series of biochemical processes that have a greater complexity. Thus, essential oils containing compounds with benzenetype structures are not easy for the insect to metabolize and detoxify, because they are more toxic than aliphatic compounds [47].

6.1. Acetylcholinesterase. Cholinesterases can be classified according to their substrate specificity as acetyl (AChE) or butyrylcholinesterase (BChE, E.C. 3.1.1.8). Inhibiting the AChE generates the accumulation of the neurotransmitter acetylcholine in neuronal synapses, which creates a state of permanent stimulation and results in a general lack of coordination in the neuromuscular system and subsequent death. Thus, the control of the activity of this enzyme is very important in determining the insecticidal capacity of natural or synthetic chemicals, with AChE consequently being the primary target of organophosphorus pesticides and carbamates $[85,86]$ as well as of some essential oils and their components [38, 49, 87, 88]. However, the AChE in resistant insects is able to change its active site or create new forms of the enzyme, in response to selective pressure after several years of the application of synthetic pesticides [86, 89-98].

Previous research has shown that essential oils from different herbs or their components can inhibit the activity of AChE. However, some of these studies employed AChE from electric eel, horse serum, or bovine erythrocytes [36, 87, 93, 94, 99-104], with future analysis of these results being difficult as the evaluation of the inhibitory effect on AChE enzyme was not performed in insects [32, 37, 93, 94, 99, 100, 104].

It has been suggested that insects may have only AChE with mixed properties of both vertebrate AChE and BChE [105]. Nevertheless, other studies have hypothesized that aphids, thrips, and probably some insects might have both $\mathrm{AChE}$ and $\mathrm{BChE}[95,105]$. In relation to this, an analysis of substrate hydrolysis at different concentrations revealed that insect cholinesterase displays activation at low substrate concentrations similar to that of the vertebrate BChE but demonstrated inhibition at high substrate concentrations

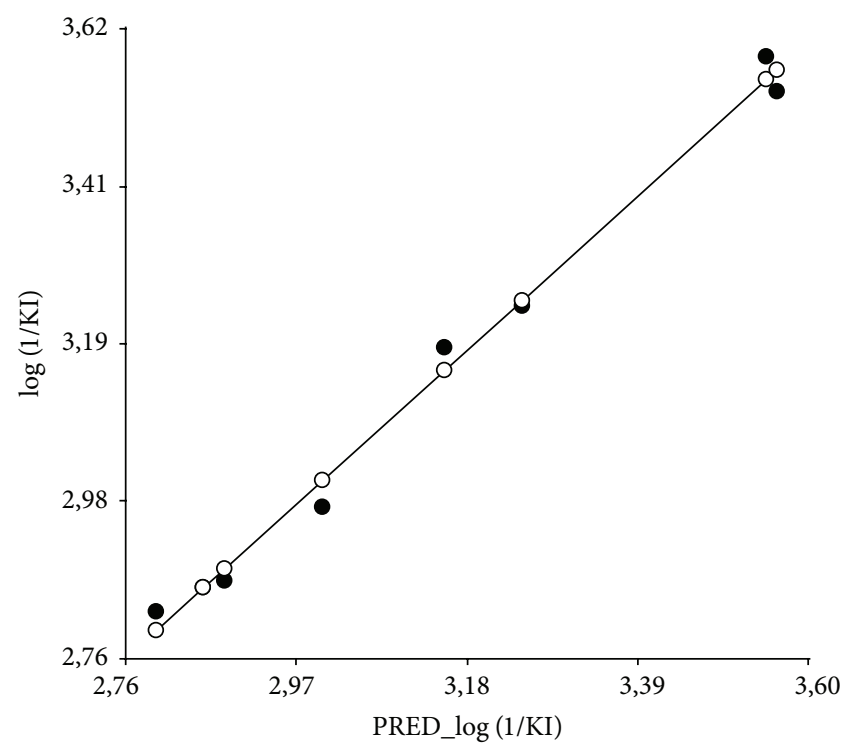

FIGURE 9: Multiple linear regression analysis (MLR) calculated to examine quantitative relationships between linear combinations of the dependent variable $\log \left(1 / \mathrm{LD}_{50}\right)$ and the predictor variables (structure and molecular properties). Plot of calculated versus experimental $\log \left(1 / \mathrm{LD}_{50}\right)$ of insecticidal activity against Triatominae bugs (vector of Chagas disease).

similar to the vertebrate AChE [89]. Moreover, Keane and Ryan [96] reported that the inhibitory activity of monoterpenes against electric eel AChE is similar to the effect of inhibiting insect AChE.

Research on the insect AChE activity has involved extracts from Musca domestica, Pieris brassicae, Galleria mellonella, Manduca sexta, Aphis citricola, Drosophila melanogaster Meigen, Apis mellifera, Blattella germanica, Pediculus humanus, and Tenebrio molitor, with few studies having used AChE from insects that had been isolated and purified, for example, Musca domestica, Rhyzopertha dominica, Lygus hesperus, Galleria mellonella, and Leptinotarsa decemlineata $[96,97]$.

The terpenes previously evaluated as inhibitors of AChE activity on electric eel or bovine erythrocytes were 1,8 cineole, $\alpha$-pinene, $\beta$-pinene, eugenol, $\alpha$-terpineol, terpinen4-ol, camphor, linalool, borneol, borneol acetate, pulegone, citral, fenchone, fenchol, 2-carene, 3-carene, verbenol, verbenone, trans-myrtanol, and myrtenol [37, 94, 96, 99, 100]. Among these monoterpenes, 1,8-cineole was found to be the best inhibitor of $\mathrm{AChE}$ activity $\left(\mathrm{IC}_{50}\right.$ values $0.015-$ $0.05 \mathrm{mg} / \mathrm{mL}$ ), and it has also been reported to show great AChE inhibitory activity in different insects $[32,37,96]$. The hydrocarbon monoterpenes $\alpha$-pinene and 3-carene showed a higher AChE inhibitory activity than their isomers $\beta$ pinene and 2-carene $[37,94,99,100]$, with the oxygenated monoterpenes such as linalool, pulegone, borneol, citral, $\alpha$-terpineol, terpinen-4-ol, verbenol, myrtenol, myrtanol, fenchone, and fenchol being the natural products most commonly used to determine AChE inhibition. Moreover, these oxygenated compounds had less inhibitory effect on AChE than hydrocarbon terpenes (between 12 and 39\% at 
concentrations equal to or greater than $1 \mathrm{mM})[32,37,94,96$, $99,100]$. Finally, Savelev et al. [99] showed that 1,8-cineole can synergize its AChE inhibitory activity when mixed with $\alpha$ pinene, with similar results being obtained when it was mixed with the $\beta$-pinene isomer. In contrast, a mixture of 1,8 -cineole with camphor had an antagonistic effect, but limonene did not inhibit the AChE activity of R. dominica [97].

6.2. Octopaminergic Sites. Octopamine is present in the nervous system of arthropods, including insects, and acts both as a neurotransmitter and as a neurohormone. In addition, some researchers believe that octopamine modulates the influence of nerve-muscle interaction. Considering pharmacological criteria, octopamine exerts its effects through the octopamine- 1 and octopamine- 2 receptors $[51,97,98]$, with its effect present throughout their union with G-proteincoupled receptors.

As the octopamine receptor binding is absent in vertebrates, it could be useful as a target for specific insecticide designs $[87,106]$. However, only a few studies have shown octopamine receptor interaction with monoterpenes. Although the modulation of octopamine receptor by phenylpropenes or terpenes could be an indicator of the insecticidal activity of these natural compounds, conflicting results have been obtained concerning the interaction between the benzene and octopamine receptors. While thymol had no effect, its isomer carvacrol acted as an agonist at a concentration of $2 \mathrm{nmol} / \mathrm{mL}$. The compounds p-cymene, eugenol, trans-anethole, vanillin, and isoeugenol were found to be antagonists of octopamine receptor [51], whereas in another study, from the electrophysiology point of view, eugenol did not show any antagonist activity [107]. Hence, there is no agreement about whether insecticidal activity of eugenol is directly related to its interaction with the octopamine receptor $[51,107,108]$. Chlordimeform, methomyl, permethrin, chlorfluazuron, malathion, trichlorfon, and some oxazolidine had agonistic effects, and eugenol, cinnamic alcohol, and phenyl methyl alcohol produced an increase in octopamine production in the German cockroach [109]. However, in contrast, limonene had no effect on the octopamine receptor of the American cockroach [51] or R. dominica [98].

Gross et al. [110], in a ligand-independent system, evaluated aliphatic and aromatic terpenes that acted as inverse agonists. One of the compounds tested, carvacrol, interacted with the octopamine receptor and altered the conformation and increased the affinity for the endogenous G-protein. Moreover, the QSAR models showed that electronic properties are the most important for the interaction of monoterpenoid with this receptor.

6.3. Gamma-Aminobutyrate (GABA). In insects, although inhibitory transmission relies mainly on three types of chloride-selective ligand-gated ion channels, namely, GABA-, glutamate-, and histamine-gated ionotropic receptors [111, 112], gamma-aminobutyrate (GABA) is a main inhibitory neurotransmitter in both vertebrates and invertebrates. Pharmacologically, the GABA receptor-chloride channel complex in insects is different from those present in mammals, as GABA receptors of insects have a regulatory function not only in the central nervous system, but also in the peripheral one $[111,113]$. The terpenoids present in the essential oil of star anise (Illicium sp.) were found to show antagonist activity on the GABA receptor of Musca domestica, with these components also having structural features that permit a differential action between the GABA receptors of insects and mammals [113].

Carvacrol, pulegone, and thymol at concentrations between $500 \mathrm{mM}$ and $1 \mathrm{mM}$ are positive allosteric GABA receptors of the American cockroach. However, $\alpha$-terpineol and linalool had no effect [54]. Waliwitiya et al. [114] reported in Phaenicia sericata that thymol interacts with the flight system and the central nervous system through the GABA complex. In addition, Priestley et al. [115] demonstrated the same result for D. melanogaster, with carvacrol and thymol being positive allosteric modulators of the GABA receptor of insects. Thus, the phenol group is an important part of the structure of terpene and exerts a positive modulation of the insect GABA receptor. Besides, the GABA receptor is more related to knocking down the insect than to insecticidal activity [53].

6.4. Tyramine Receptor. Tyramine is a biogenic amine that is biosynthetically and functionally related to octopamine, with this amine mediating the intracellular changes and producing second messengers such as cAMP and/or $\mathrm{Ca}^{2+}$. Although tyramine is considered as a neurotransmitter, it is pharmacologically different from octopamine [116]. Enan [116] reported insecticidal activity of thymol, carvacrol, $\alpha$ terpineol, p-cymene, and carvone on D. melanogaster, with the data indicating that thymol and carvacrol interact with the tyramine receptor without any significant differences and that the presence of a hydroxyl substituent on the benzene ring is critical for good insecticidal activity.

6.5. Growth Regulators. The use of natural compounds at sublethal concentrations can control insect pest populations by affecting growth and reproduction [117]. Terpenes can cause deformation of adult insect emergence or the lack of eggs, similar to growth-regulating hormones [118] such as juvenile hormone. Among the more active terpenes, geraniol causes a high rate of deformities in adults [119]. While the egg stage was found to be the most resistant, the larva was the most sensitive [120-122]. Oxide piperitenone retarded the reproduction of the malaria vector Anopheles stephensi. Moreover, oxide piperitenone also completely inhibited egg hatching at a dose of $750 \mu \mathrm{g} / \mathrm{mL}$ in an ovicidal assay, as well as inhibited oviposition, but no changes were observed in adult development [123]. When Acanthoscelides obtectus larvae and pupae were exposed to sublethal concentrations of lavender, rosemary, and Eucalyptus essential oil vapor, the results revealed an increase in the development times of larvae and pupae along with a reduction in the longevity and fecundity of the emerged female adults [124].

\section{Discussion}

The quantitative structure-activity relationship (QSAR) is a mathematical expression by which the chemical structure 
is quantitatively correlated with well-known processes such as biological activity or chemical reactivity. The biological activity of a chemical compound depends on the ability to reach the specific target molecule and its subsequent capacity to interact with it ([125] and references therein). Hence, the three major types of interactions that the modeller must deal with are the hydrophobic, electronic, and steric ones [126]. For the different insects reported in the present study, the chemical characteristics represent a compound's ability to reach the target site, with the descriptors that mainly explained the insecticidal activities being BP, VP, and $\log P$.

As the BP and VP descriptors represent the volatility of the compounds, it could be expected that these properties predict a higher activity in the less volatile compounds. In contrast, the opposite effect would be expected in the fumigant toxicity tests. The $\log P$ descriptor represents the lipophilicity of the compounds, which determines their ability to penetrate into the plasma membranes. In the obtained models, this descriptor only appeared in (8) (hydrocarbon compounds), indicating that an increase in lipophilicity leads to a decrease in activity. This is in agreement with Jang et al. [42], who suggested that the hydrocarbon monoterpenes with high $\log P$ values are less bioactive than those with lower $\log P$, because they can be accumulated in the cuticle of insects and thus inhibit their traffic to the target site [47].

Other descriptors that largely contributed in the obtained models were MV and the number of rings. These structural characteristics are related to the steric aspect of the insecticidal activity of the compounds. Our obtained models revealed a higher activity of compounds with fewer rings and lower molar volume, which might indicate the importance of steric aspect in the interaction of molecules with the active sites of targets. This is in agreement with Rice and Coats [17], who suggested that monocyclic terpenes are more toxic than bicyclic on the German cockroach. The ASA descriptors in (4), (5), (6), and (7) indicate the importance of the interaction of the compounds with their target or vehicle, which is consistent with Lee et al. [52] and Jang et al. [42], who suggested the importance of interaction with water molecules on the surface of the insect respiratory system (tracheoles) and the bioactivity of these compounds. Finally, chemical descriptors such as RI, ST, and parachor demonstrate the importance of the interaction of monoterpenes with other molecules.

The results of several studies have suggested that insecticidal activity depends on several factors such as dose, species assayed, toxicity methods, and target [2, 44, 50, 127]. However, due to discrepancies in the methodologies used by different authors, comparison of the insecticidal effects for the evaluated compounds is difficult using these investigations. In addition, several authors evaluated the bioactivity of compounds with diverse chemical structures, which makes it difficult to attribute their activities to a specific chemical property. We think that a joint effort should be made to standardize the methodology used and a standard compound (universal) could be added that would allow a comparison of the activity using the results of different authors.

In conclusion, the present work demonstrated that molecular properties or descriptors are important for explaining the bioactivity of terpene compounds on insects. The resulting models employed steric, electronic, and transport features to predict the bioactivity, with the results suggesting that the activity of these compounds depends on their ability to reach the targets, and their capability of interacting with them. In addition, the mathematical expression obtained by the QSAR analysis can be used to predict the insecticidal activities of structurally related molecules. Our findings may provide an important contribution in the search for new compounds with insecticidal activity. In addition, the development of natural insecticides has some advantages; for example, they are naturally occurring, they have low toxicity against nontarget organism, they do not persist in the environment, they have the capability to not generate resistant populations, and they have nonrestricted use [128, 129]. Based on these properties and despite the high cost of natural products, the benefits related with their use could be an alternative to synthetic pesticide.

\section{Abbreviations}

ASA: Solvent-accessible surface area calculated using the radius of the solvent $(1.4 \AA$ for water molecule)

ASA+: Solvent-accessible surface area of all atoms with positive partial charge (strictly greater than 0 )

ASA-: Solvent-accessible surface area of all atoms with negative partial charge (strictly less than 0)

ASA H: Solvent-accessible surface area of all hydrophobic $(|q i|<0.125)$ atoms $(|q i|$ is the absolute value of the partial charge of the atom)

ASA P: Solvent-accessible surface area of all polar $(|q i|>0.125)$ atoms $(|q i|$ is the absolute value of the partial charge of the atom)

BP: $\quad$ Boiling point

DP3D: Plane deviation 3D

FW: $\quad$ Formula weight

HBA: Hydrogen bond acceptor

HBD: Hydrogen bond donor

$\log P$ : Logarithm of the octanol-water partition coefficient

MR: Molar refractivity

MV: Molar volume

OE: Orbital electronegativity

P: Polarizability

Pi E: Pi energy

pka: Logarithm of dissociation constant

PSA: Polar surface area

RI: $\quad$ Refractive index

ST: $\quad$ Surface tension

VE: Vaporization enthalpy

VP: $\quad$ Vapor pressure.

\section{Competing Interests}

The authors declare that there are no competing interests regarding the publication of this paper. 


\section{Acknowledgments}

This research was supported by grants from the Secretaría de Ciencia y Técnica de la Universidad Nacional de Córdoba and Consejo Nacional de Investigaciones Científicas y Técnicas (CONICET). José S. Dambolena, María P. Zunino, Romina P. Pizzolitto, and Julio A. Zygadlo are Career Members of CONICET. Jimena M. Herrera and Vanessa A. Areco have a fellowship from CONICET. The authors thank Dr. Paul D. Hobson for revising the English manuscript.

\section{References}

[1] A. Michaelakis, D. Papachristos, A. Kimbaris, G. Koliopoulos, A. Giatropoulos, and M. G. Polissiou, "Citrus essential oils and four enantiomeric pinenes against Culex pipiens (Diptera: Culicidae)," Parasitology Research, vol. 105, no. 3, pp. 769-773, 2009.

[2] H. Tunaz, M. K. Er, and A. A. Işikber, "Fumigant toxicity of plant essential oils and selected monoterpenoid components against the adult german cockroach, Blattella germanica (L.) (Dictyoptera: Blattellidae)," Turkish Journal of Agriculture and Forestry, vol. 33, no. 2, pp. 211-217, 2009.

[3] A. C. Toloza, A. Lucía, E. Zerba, H. Masuh, and M. I. Picollo, "Eucalyptus essential oil toxicity against permethrin-resistant Pediculus humanus capitis (Phthiraptera: Pediculidae)," Parasitology Research, vol. 106, no. 2, pp. 409-414, 2010.

[4] F. Lardeux, S. Depickère, S. Duchon, and T. Chavez, "Insecticide resistance of Triatoma infestans (Hemiptera, Reduviidae) vector of Chagas disease in Bolivia," Tropical Medicine and International Health, vol. 15, no. 9, pp. 1037-1048, 2010.

[5] M. B. Isman, "Botanical insecticides, deterrents, and repellents in modern agriculture and an increasingly regulated world," Annual Review of Entomology, vol. 51, pp. 45-66, 2006.

[6] ChemAxon Soft, http://www.cambridgesoft.com/.

[7] Chemspider, 2014, http://www.chemspider.com/.

[8] J. A. Di Rienzo, F. Casanoves, M. G. Balzarini, L. Gonzalez, M. Tablada, and C. W. Robledo, Infostat Versión 2010, Grupo Infostat, FCA, Universidad Nacional de Córdoba, Córdoba, Argentina, 2010.

[9] C. J. Ko and D. M. Elston, "Pediculosis," Journal of the American Academy of Dermatology, vol. 50, no. 1, pp. 1-12, 2004.

[10] D. Robinson, N. Leo, P. Prociv, and S. C. Barker, "Potential role of head lice, Pediculus humanus capitis, as vectors of Rickettsia prowazekii," Parasitology Research, vol. 90, no. 3, pp. 209-211, 2003.

[11] A. C. Toloza, J. Zygadlo, G. M. Cueto, F. Biurrun, E. Zerba, and M. I. Picollo, "Fumigant and repellent properties of essential oils and component compounds against permethrinresistant Pediculus humanus capitis (Anoplura: Pediculidae) from Argentina," Journal of Medical Entomology, vol. 43, no. 5, pp. 889-895, 2006.

[12] A. Gallardo, G. Mougabure Cueto, and M. I. Picollo, "Pediculus humanus capitis (head lice) and Pediculus humanus humanus (body lice): response to laboratory temperature and humidity and susceptibility to monoterpenoids," Parasitology Research, vol. 105, no. 1, pp. 163-167, 2009.

[13] A. C. Toloza, Bioactividad y Toxicidad de Componentes de Aceites Esenciales Vegetales, en Pediculus Humanus Capitis (Phthiraptera: Pediculidae) Resistentes a Insecticidas Piretroides, Universidad de Buenos Aires, Facultad de Ciencias Exactas y Naturales, 2010.
[14] I. F. Burgess, E. R. Brunton, and N. A. Burgess, "Clinical trial showing superiority of a coconut and anise spray over permethrin $0.43 \%$ lotion for head louse infestation, ISRCTN96469780," European Journal of Pediatrics, vol. 169, no. 1, pp. 55-62, 2010.

[15] I. F. Burgess, "Human lice and their control," Annual Review of Entomology, vol. 49, pp. 457-481, 2004.

[16] C. V. Vassena, G. Mougabure Cueto, P. González Audino, R. A. Alzogaray, E. N. Zerba, and M. I. Picollo, "Prevalence and levels of permethrin resistance in Pediculus humanus capitis de Geer (Anoplura: Pediculidae) from Buenos Aires, Argentina," Journal of Medical Entomology, vol. 40, no. 4, pp. 447-450, 2003.

[17] P. J. Rice and J. R. Coats, "Insecticidal properties of several monoterpenoids to the house fly (Diptera: Muscidae), red flour beetle (Coleoptera: Tenebrionidae), and southern corn rootworm (Coleoptera: Chrysomelidae)," Journal of Economic Entomology, vol. 87, no. 5, pp. 1172-1179, 1994.

[18] M. Isman, "Pesticides based on plant essential oils," Pesticide Outlook, vol. 10, no. 2, pp. 68-72, 1999.

[19] M. Lahlou, R. Berrada, A. Agoumi, and M. Hmamouchi, "The potential effectiveness of essential oils in the control of human head lice in Morocco," International Journal of Aromatherapy, vol. 10, no. 3-4, pp. 108-123, 2001.

[20] F. A. Oladimeji, O. O. Orafidiya, T. A. B. Ogunniyi, and T. A. Adewunmi, "Pediculocidal and scabicidal properties of Lippia multiflora essential oil," Journal of Ethnopharmacology, vol. 72, no. 1-2, pp. 305-311, 2000.

[21] Y.-C. Yang, H.-S. Lee, J. M. Clark, and Y.-J. Ahn, "Insecticidal activity of plant essential oils against Pediculus humanus capitis (Anoplura: Pediculidae)," Journal of Medical Entomology, vol. 41, no. 4, pp. 699-704, 2004.

[22] I. M. Cestari, S. J. Sarti, C. M. Waib, and A. C. Branco Jr., "Evaluation of the potential insecticide activity of Tagetes minuta (Asteraceae) essential oil against the head lice Pediculus humanus capitis (Phthiraptera: Pediculidae)," Neotropical Entomology, vol. 33, no. 6, pp. 805-807, 2004.

[23] A. L. Tapondjou, C. Adler, D. A. Fontem, H. Bouda, and C. Reichmuth, "Bioactivities of cymol and essential oils of Cupressus sempervirens and Eucalyptus saligna against Sitophilus zeamais Motschulsky and Tribolium confusum du Val," Journal of Stored Products Research, vol. 41, no. 1, pp. 91-102, 2005.

[24] E. M. Williamson, C. M. Priestley, and I. F. Burgess, "An investigation and comparison of the bioactivity of selected essential oils on human lice and house dust mites," Fitoterapia, vol. 78, no. 7-8, pp. 521-525, 2007.

[25] V. Jadhav, A. Kore, and V. J. Kadam, "In-vitro pediculicidal activity of Hedychium spicatum essential oil," Fitoterapia, vol. 78, no. 7-8, pp. 470-473, 2007.

[26] A. C. Toloza, J. Zygadlo, F. Biurrun, A. Rotman, and M. I. Picollo, "Bioactivity of Argentinean essential oils against permethrin-resistant head lice, Pediculus humanus capitis," Journal of Insect Science, vol. 10, article 185, 2010.

[27] S. C. Barker and P. M. Altman, "An ex vivo, assessor blind, randomised, parallel group, comparative efficacy trial of the ovicidal activity of three pediculicides after a single applicationmelaleuca oil and lavender oil, eucalyptus oil and lemon tea tree oil, and a 'suffocation' pediculicide," BMC Dermatology, vol. 11, article 14, 2011.

[28] P. González Audino, C. Vassena, E. Zerba, and M. I. Picollo, "Malathion for treatment of Pediculus humanus var capitis infestation," Archives of Dermatological Research, vol. 299, pp. 389-392, 2007. 
[29] Y.-C. Yang, S.-H. Lee, W.-J. Lee, D.-H. Choi, and Y.-J. Ahn, “Ovicidal and adulticidal effects of Eugenia caryophyllata bud and leaf oil compounds on Pediculus capitis," Journal of Agricultural and Food Chemistry, vol. 51, no. 17, pp. 4884-4888, 2003.

[30] Y.-C. Yang, H.-S. Lee, S. H. Lee, J. M. Clark, and Y.-J. Ahn, "Ovicidal and adulticidal activities of Cinnamomum zeylanicum bark essential oil compounds and related compounds against Pediculus humanus capitis (Anoplura: Pediculicidae)," International Journal for Parasitology, vol. 35, no. 14, pp. 15951600, 2005.

[31] C. M. Priestley, I. F. Burgess, and E. M. Williamson, "Lethality of essential oil constituents towards the human louse, Pediculus humanus, and its eggs," Fitoterapia, vol. 77, no. 4, pp. 303-309, 2006.

[32] A. C. Toloza, A. Lucia, E. Zerba, H. Masuh, and M. I. Picollo, "Interspecific hybridization of Eucalyptus as a potential tool to improve the bioactivity of essential oils against permethrinresistant head lice from Argentina," Bioresource Technology, vol. 99, no. 15, pp. 7341-7347, 2008.

[33] Y.-C. Yang, S. H. Lee, J. M. Clark, and Y.-J. Ahn, "Ovicidal and adulticidal activities of origanum majorana essential oil constituents against insecticide-susceptible and pyrethroid/malathion-resistant Pediculus humanus capitis (Anoplura: Pediculidae)," Journal of Agricultural and Food Chemistry, vol. 57, no. 6, pp. 2282-2287, 2009.

[34] P. Gonzalez-Audino, M. I. Picollo, A. Gallardo, A. Toloza, C. Vassena, and G. Mougabure-Cueto, "Comparative toxicity of oxygenated monoterpenoids in experimental hydroalcoholic lotions to permethrin-resistant adult head lice," Archives of Dermatological Research, vol. 303, no. 5, pp. 361-366, 2011.

[35] A. Gallardo, M. I. Picollo, P. González-Audino, and G. Mougabure-Cueto, "Insecticidal activity of individual and mixed monoterpenoids of geranium essential oil against pediculus humanus capitis (Phthiraptera: Pediculidae)," Journal of Medical Entomology, vol. 49, no. 2, pp. 332-335, 2012.

[36] M. Miyazawa, H. Watanabe, and H. Kameoka, "Inhibition of acetylcholinesterase activity by monoterpenoids with a $p$ menthane skeleton," Journal of Agricultural and Food Chemistry, vol. 45, no. 3, pp. 677-679, 1997.

[37] M. D. López and M. J. Pascual-Villalobos, "Mode of inhibition of acetylcholinesterase by monoterpenoids and implications for pest control," Industrial Crops and Products, vol. 31, no. 2, pp. 284-288, 2010.

[38] M. I. Picollo, A. C. Toloza, G. Mougabure Cueto, J. Zygadlo, and E. Zerba, "Anticholinesterase and pediculicidal activities of monoterpenoids," Fitoterapia, vol. 79, no. 4, pp. 271-278, 2008.

[39] T. Hideyuk and M. Mitsuo, "Inhibition of acetylcholinesterase activity by essential oil from Bergamot," Koryo Terupen Oyobi Seiyu Kagaku Ni Kansuru Toronkai Koen Yoshishu, vol. 45, pp. 435-436, 2001.

[40] J. A. Pickett, M. A. Birkett, and J. G. Logan, "DEET repels ORNery mosquitoes," Proceedings of the National Academy of Sciences of the United States of America, vol. 105, no. 36, pp. 13195-13196, 2008.

[41] K. Y. Mumcuoglu, S. Magdassi, J. Miller et al., "Repellency of citronella for head lice: double-blind randomized trial of efficacy and safety," Israel Medical Association Journal, vol. 6, no. 12, pp. 756-759, 2004.

[42] Y.-S. Jang, Y.-C. Yang, D.-S. Choi, and Y.-J. Ahn, "Vapor phase toxicity of marjoram oil compounds and their related monoterpenoids to Blattella germanica (Orthoptera: Blattellidae)," Journal of Agricultural and Food Chemistry, vol. 53, no. 20, pp. 7892-7898, 2005.
[43] D. Laurent, L. A. Vilaseca, J.-M. Chantraine, C. Ballivian, G. Saavedra, and R. Ibañez, "Insecticidal activity of essential oils on triatoma infestans," Phytotherapy Research, vol. 11, no. 4, pp. 285-290, 1997.

[44] C. Yoon, S.-H. Kang, J.-O. Yang, D.-J. Noh, P. Indiragandhi, and G.-H. Kim, "Repellent activity of citrus oils against the cockroaches Blattella germanica, Periplaneta americana and P. fuliginosa," Journal of Pesticide Science, vol. 34, no. 2, pp. 77-88, 2009.

[45] USEPA, Environmental Protection Agency, Exemption of certain pesticide substances from federal insecticide, fungicide, and rodenticide act requirements, U.S, 1996.

[46] A. K. Phillips and A. G. Appel, "Fumigant toxicity of essential oils to the German cockroach (Dictyoptera: Blattellidae)," Journal of Economic Entomology, vol. 103, no. 3, pp. 781-790, 2010.

[47] S. J. Yu, The Toxicology and Biochemistry of Insecticides, CRC \& Taylor \& Francis, Boca Raton, Fla, USA, 2008.

[48] A. K. Phillips, A. G. Appel, and S. R. Sims, "Topical toxicity of essential oils to the German cockroach (Dictyoptera: Blattellidae)," Journal of Economic Entomology, vol. 103, no. 2, pp. 448459, 2010.

[49] H.-J. Yeom, J. S. Kang, G.-H. Kim, and I.-K. Park, "Insecticidal and acetylcholine esterase inhibition activity of apiaceae plant essential oils and their constituents against adults of German cockroach (Blattella germanica)," Journal of Agricultural and Food Chemistry, vol. 60, no. 29, pp. 7194-7203, 2012.

[50] W.-C. Jung, Y.-S. U. Jang, T. T. Hieu, C.-K. Lee, and Y.-J. Ahn, "Toxicity of Myristica fragrans seed compounds against Blattella germanica (Dictyoptera: Blattellidae)," Journal of Medical Entomology, vol. 44, no. 3, pp. 524-529, 2007.

[51] E. Enan, "Insecticidal activity of essential oils: octopaminergic sites of action," Comparative Biochemistry and Physiology-C Toxicology and Pharmacology, vol. 130, no. 3, pp. 325-337, 2001.

[52] S. Lee, C. J. Peterson, and J. R. Coats, "Fumigation toxicity of monoterpenoids to several stored product insects," Journal of Stored Products Research, vol. 39, no. 1, pp. 77-85, 2003.

[53] D. B. Sattelle, S. C. R. Lummis, J. F. H. Wong, and J. J. Rauh, "Pharmacology of insect GABA receptors," Neurochemical Research, vol. 16, no. 3, pp. 363-374, 1991.

[54] F. Tong and J. R. Coats, "Effects of monoterpenoid insecticides on $\left[{ }^{3} \mathrm{H}\right]$-TBOB binding in house fly GABA receptor and ${ }^{36} \mathrm{Cl}^{-}$ uptake in American cockroach ventral nerve cord," Pesticide Biochemistry and Physiology, vol. 98, no. 3, pp. 317-324, 2010.

[55] W. X. Zhu, K. Zhao, S. S. Chu, and Z. L. Liu, "Evaluation of essential oil and its three main active ingredients of Chinese chenopodium ambrosioides (family: Chenopodiaceae) against blattella germanica," Journal of Arthropod-Borne Diseases, vol. 6, no. 2, pp. 90-97, 2012.

[56] H.-J. Yeom, J. Kang, S.-W. Kim, and I.-K. Park, "Fumigant and contact toxicity of Myrtaceae plant essential oils and blends of their constituents against adults of German cockroach (Blattella germanica) and their acetylcholinesterase inhibitory activity," Pesticide Biochemistry and Physiology, vol. 107, no. 2, pp. 200206, 2013.

[57] Y.-J. Ahn, S.-B. Lee, H.-S. Lee, and G.-H. A. Kim, "Insecticidal and acaricidal activity of carvacrol and $\beta$-thujaplicine derived from Thujopsis dolabrata var. hondai sawdust," Journal of Chemical Ecology, vol. 24, no. 1, pp. 81-90, 1998.

[58] Y. B. Yilmaz and H. Tunaz, "Fumigant toxicity of some plant essential oils and their selected monoterpenoid components against adult American cockroach, Periplaneta americana (Dictyoptera: Blattidae)," Turkiye Entomoloji Dergisi, vol. 37, no. 3, pp. 319-328, 2013. 
[59] K.-S. Chang and Y.-J. Ahn, "Fumigant activity of (E)-anethole identified in Illicium verum fruit against Blattella germanica," Pest Management Science, vol. 58, no. 2, pp. 161-166, 2002.

[60] S. P. Ngoh, L. E. W. Choo, F. Y. Pang, Y. Huang, M. R. Kini, and S. H. Ho, "Insecticidal and repellent properties of nine volatile constituents of essential oils against the American cockroach, Periplaneta americana (L.)," Pesticide Science, vol. 54, no. 3, pp. 261-268, 1998.

[61] G. J. Tortora, B. R. Funke, and C. L. Case, Microbiology: An Introduction, Benjamin Cummings, San Francisco, Calif, USA, 9th edition, 2007.

[62] F. Matsumura, Toxicology of Insecticides, Plenum, New York, NY, USA, 2nd edition, 1985.

[63] S. Yacoub, A. O. Mocumbi, and M. H. Yacoub, "Neglected tropical cardiomyopathies: I. Chagas disease," Heart, vol. 94, no. 2, pp. 244-248, 2008.

[64] World Health Organization, "Control of Chagas disease," WHO Technical Report Series 905, World Health Organization, Geneva, Switzerland, 2002.

[65] D. Barreto-Santana, J. Starling, R. Gurgel-Gonçalves, and C. A. C. Cuba-Cuba, "Comparative biology and feeding behavior of Rhodnius neglectus and Rhodnius robustus (Triatominae) under laboratory conditions," Revista da Sociedade Brasileira de Medicina Tropical, vol. 44, no. 4, pp. 490-495, 2011.

[66] E. N. Zerba, "Susceptibility and resistance to insecticides of Chagas disease vectors," Medicina, vol. 59, no. 2, pp. 41-46, 1999.

[67] I. Amelotti, S. S. Catalá, and D. E. Gorla, "Experimental evaluation of insecticidal paints against Triatoma infestans (Hemiptera: Reduviidae), under natural climatic conditions," Parasites and Vectors, vol. 2, pp. 30-37, 2009.

[68] J. C. P. Dias and A. Jemmio, "About an insecticidal paint for controlling Triatoma infestans, in Bolivia," Revista da Sociedade Brasileira de Medicina Tropical, vol. 41, no. 1, pp. 79-81, 2008.

[69] C. V. Vassena, M. I. Picollo, P. Santo Orihuela, and E. N. Zerba, "Desarrollo y manejo de la resistencia a insecticidas piretroides en Triatoma infestans: situación en Bolivia," in Triatominos de Bolivia y la Enfermedad de Chagas, M. Rojas Cortez, Ed., pp. 229-255, Ministerio de Salud y Deportes, Unidad de Epidemiología, Programa Nacional de Chagas, La Paz, Bolivia, 2007.

[70] A. C. Toloza, M. Germano, G. M. Cueto, C. Vassena, E. Zerba, and M. I. Picollo, "Differential patterns of insecticide resistance in eggs and first instars of Triatoma infestans (Hemiptera: Reduviidae) from Argentina and Bolivia," Journal of Medical Entomology, vol. 45, no. 3, pp. 421-426, 2008.

[71] G. M. Cueto, E. Zerba, and M. I. Picollo, "Biological effect of 1-dodecanol in teneral and post-teneral Rhodnius prolixus and Triatoma infestans (Hemiptera: Reduviidae)," Memórias do Instituto Oswaldo Cruz, vol. 100, no. 1, pp. 59-61, 2005.

[72] M. P. Juárez and G. C. Fernández, "Cuticular hydrocarbons of triatomines," Comparative Biochemistry and Physiology Part A: Molecular \& Integrative Physiology, vol. 147, no. 3, pp. 711-730, 2007.

[73] J.-L. Boevé, D. Voigt, and S. N. Gorb, “Crystalline wax coverage of the cuticle in easy bleeding sawfly larvae," Arthropod Structure and Development, vol. 40, no. 2, pp. 186-189, 2011.

[74] L. M. Cocchiararo-Bastias, S. J. Mijailovsky, G. M. CalderonFernández, A. N. L. Figueiras, and M. P. Juárez, "Epicuticle lipids mediate mate recognition in triatoma infestans," Journal of Chemical Ecology, vol. 37, no. 3, pp. 246-252, 2011.

[75] A. N. L. Figueiras, J. R. Girotti, S. J. Mijailovsky, and M. P. Juárez, "Epicuticular lipids induce aggregation in Chagas disease vectors," Parasites and Vectors, vol. 2, article 8, pp. 1-7, 2009.

[76] S. P. Gomes and S. Favero, "Assessment of the insecticidal potential of Eucalyptus urograndis essential oil against Rhodnius neglectus lent (Hemiptera: Reduviidae)," Neotropical Entomology, vol. 42, no. 4, pp. 431-435, 2013.

[77] A. M. Pohlit, A. R. Rezende, E. L. Lopes Baldin, N. P. Lopes, and V.F. de Andrade Neto, "Plant Extracts, isolated phytochemicals, and plant-derived agents which are lethal to arthropod vectors of human tropical diseases-a review," Planta Medica, vol. 77, pp. 618-630, 2011.

[78] J. A. Terriquez, S. A. Klotz, E. A. Meister, J. H. Klotz, and J. O. Schmidt, "Repellency of DEET, picaridin, and three essential oils to Triatoma rubida (Hemiptera: Reduviidae: Triatominae)," Journal of Medical Entomology, vol. 50, no. 3, pp. 664-667, 2013.

[79] K. L. Sukontason, K. Sukontason, N. Boonchu, and S. Piangjai, "Some ultrastructural superficial changes in house fly (Diptera: Muscidae) and blow fly (Diptera: Calliphoridae) larvae induced by eucalyptol oil," Revista do Instituto de Medicina Tropical de São Paulo, vol. 46, no. 5, pp. 263-267, 2004.

[80] A. A. Ferrero, J. O. Werdin González, and C. Sánchez Chopa, "Biological activity of Schinus molle on Triatoma infestans," Fitoterapia, vol. 77, no. 5, pp. 381-383, 2006.

[81] M. D. Buescher, L. C. Rutledge, R. A. Wirtz, and J. H. Nelson, "Laboratory repellent tests against Rhodnius prolixus (Heteroptera: Reduviidae)," Journal of Medical Entomology, vol. 22, no. 1, pp. 49-53, 1985.

[82] R. A. Alzogaray, A. Fontan, and E. N. Zerba, "Repellency of deet to nymphs of Triatoma infestans," Medical and Veterinary Entomology, vol. 14, no. 1, pp. 6-10, 2000.

[83] M. I. Picollo, E. Seccacini, C. Vassena, and E. Zerba, "Feeding and mating deterrency by sulfhydryl reagents in Triatoma infestans," Acta Tropica, vol. 52, no. 4, pp. 297-307, 1993.

[84] IRAC, Insecticide Resistance Action committee MoA Classification, 7.1, 2007.

[85] M. I. P. de Villar, E. N. Zerba, E. Wood, and S. de Licastro, "Neurogenesis and occurrence of cholinesterase in eggs of Triatoma infestans," Comparative Biochemistry and Physiology Part C: Comparative Pharmacology, vol. 65, no. 1, pp. 65-70, 1980.

[86] M. I. P. de Villar, E. J. Wood, E. N. Zerba, S. A. de Licastro, and N. Casabe, "Cholinesterases and eserine-resistant esterases in the developing embryo of Triatoma infestans and its role as targets for inhibition in the ovicide action of parathion," Comparative Biochemistry and Physiology. Part C, Comparative, vol. 67, no. 1, pp. 55-59, 1980.

[87] R. S. Rattan, "Mechanism of action of insecticidal secondary metabolites of plant origin," Crop Protection, vol. 29, no. 9, pp. 913-920, 2010.

[88] J. A. Anderson and J. R. Coats, "Acetylcholinesterase inhibition by nootkatone and carvacrol in arthropods," Pesticide Biochemistry and Physiology, vol. 102, no. 2, pp. 124-128, 2012.

[89] L. Brochier, Y. Pontié, M. Willson et al., "Involvement of deacylation in activation of substrate hydrolysis by drosophila acetylcholinesterase," Journal of Biological Chemistry, vol. 276, no. 21, pp. 18296-18302, 2001.

[90] M. Weill, P. Fort, A. Berthomieu, M. P. Dubois, N. Pasteur, and M. Raymond, "A novel acetylcholinesterase gene in mosquitoes codes for the insecticide target and is non-homologous to the ace gene in Drosophila," Proceedings of the Royal Society B: Biological Sciences, vol. 269, no. 1504, pp. 2007-2016, 2002. 
[91] W. T. Kim and K. S. Boo, "Insecticide sensitivity of acetylcholinesterase from a Korean Housefly (Musca domestica) strain to organophosphates," Journal of Asia-Pacific Entomology, vol. 7, no. 2, pp. 187-193, 2004.

[92] E. Huchard, M. Martinez, H. Alout et al., "Acetylcholinesterase genes within the Diptera: takeover and loss in true flies," Proceedings of the Royal Society B: Biological Sciences, vol. 273, no. 1601, pp. 2595-2604, 2006.

[93] I. Orhan, S. Aslan, M. Kartal, B. Şener, and K. Hüsnü Can Başer, "Inhibitory effect of Turkish Rosmarinus officinalis L. on acetylcholinesterase and butyrylcholinesterase enzymes," Food Chemistry, vol. 108, no. 2, pp. 663-668, 2008.

[94] S. Dohi, M. Terasaki, and M. Makino, "Acetylcholinesterase inhibitory activity and chemical composition of commercial essential oils," Journal of Agricultural and Food Chemistry, vol. 57, no. 10, pp. 4313-4318, 2009.

[95] A. P. Brestkin, A. E. Khovanskikh, E. B. Maizel, S. N. Moralev, K. V. Novozhilov, and I. N. Sazanova, "Cholinesterases of aphids. Sensitivity of cholinesterases of spring grain aphid Schizaphis gramina rond. To some tetraalkylammonium ions and alcohols," Insect Biochemistry and Molecular Biology, vol. 22, no. 7, pp. 769-775, 1992.

[96] S. Keane and M. F. Ryan, "Purification, characterisation, and inhibition by monoterpenes of acetylcholinesterase from the waxmoth, Galleria mellonella (L.)," Insect Biochemistry and Molecular Biology, vol. 29, no. 12, pp. 1097-1104, 1999.

[97] M. Kostyukovsky, A. Rafaeli, C. Gileadi, N. Demchenko, and E. Shaaya, "Activation of octopaminergic receptors by essential oil constituents isolated from aromatic plants: possible mode of action against insect pests," Pest Management Science, vol. 58, no. 11, pp. 1101-1106, 2002.

[98] H. Verlinden, R. Vleugels, E. Marchal et al., "The cloning, phylogenetic relationship and distribution pattern of two new putative GPCR-type octopamine receptors in the desert locust (Schistocerca gregaria)," Journal of Insect Physiology, vol. 56, no. 8, pp. 868-875, 2010.

[99] S. Savelev, E. Okello, N. S. L. Perry, R. M. Wilkins, and E. K. Perry, "Synergistic and antagonistic interactions of anticholinesterase terpenoids in Salvia lavandulaefolia essential oil," Pharmacology Biochemistry and Behavior, vol. 75, no. 3, pp. 661668, 2003.

[100] M. Miyazawa and C. Yamafuji, "Inhibition of acetylcholinesterase activity by bicyclic monoterpenoids," Journal of Agricultural and Food Chemistry, vol. 53, no. 5, pp. 1765-1768, 2005.

[101] M. Miyazawa and C. Yamafuji, "Inhibition of acetylcholinesterase activity by tea tree oil and constituent terpenoids," Flavour and Fragrance Journal, vol. 21, no. 2, pp. 198-201, 2006.

[102] A. Ferreira, C. Proença, M. L. M. Serralheiro, and M. E. M. Araújo, "The in vitro screening for acetylcholinesterase inhibition and antioxidant activity of medicinal plants from Portugal," Journal of Ethnopharmacology, vol. 108, no. 1, pp. 3137, 2006.

[103] C. Mills, B. J. Cleary, J. F. Gilmer, and J. J. Walsh, "Inhibition of acetylcholinesterase by Tea Tree oil," Journal of Pharmacy and Pharmacology, vol. 56, no. 3, pp. 375-379, 2004.

[104] M. Fujiwaraj, N. Yagi, and M. Miyazawa, "Acetylcholinesterase inhibitory activity of volatile oil from Peltophorum dasyrachis kurz ex bakar (Yellow Batai) and bisabolane-type sesquiterpenoids," Journal of Agricultural and Food Chemistry, vol. 58, no. 5, pp. 2824-2829, 2010.

[105] J.-R. Gao and K. Y. Zhu, "An acetylcholinesterase purified from the greenbug (Schizaphis graminum) with some unique enzymological and pharmacological characteristics," Insect Biochemistry and Molecular Biology, vol. 31, no. 11, pp. 1095-1104, 2001.

[106] H. Verlinden, R. Vleugels, E. Marchal et al., "The role of octopamine in locusts and other arthropods," Journal of Insect Physiology, vol. 56, no. 8, pp. 854-867, 2010.

[107] D. N. Price and M. S. Berry, "Comparison of effects of octopamine and insecticidal essential oils on activity in the nerve cord, foregut, and dorsal unpaired median neurons of cockroaches," Journal of Insect Physiology, vol. 52, no. 3, pp. 309319, 2006.

[108] E. E. Enan, "Molecular and pharmacological analysis of an octopamine receptor from American cockroach and fruit fly in response to plant essential oils," Archives of Insect Biochemistry and Physiology, vol. 59, no. 3, pp. 161-171, 2005.

[109] C. Pan, W. Li, Y. Wang, and S. Jiang, "Octopamine levels in Blattella germanica L. tissues by capillary gas chromatography with electron capture detection," International Journal of Molecular Sciences, vol. 6, no. 3-5, pp. 188-197, 2005.

[110] A. D. Gross, M. J. Kimber, T. A. Day, P. Ribeiro, and J. R. Coats, "Quantitative Structure-Activity Relationships (QSARs) of monoterpenoids at an expressed American cockroach octopamine receptor," in Pest Management with Natural Products, vol. 97 of ACS Symposium Series, chapter 7, pp. 97-110, American Chemical Society, 2013.

[111] S. D. Buckingham, P. C. Biggin, B. M. Sattelle, L. A. Brown, and D. B. Sattelle, "Insect GABA receptors: splicing, editing, and targeting by antiparasitics and insecticides," Molecular Pharmacology, vol. 68, no. 4, pp. 942-951, 2005.

[112] A. K. El Hassani, J. P. Dupuis, M. Gauthier, and C. Armengaud, "Glutamatergic and GABAergic effects of fipronil on olfactory learning and memory in the honeybee," Invertebrate Neuroscience, vol. 9, no. 2, pp. 91-100, 2009.

[113] T. J. Schmidt, M. Gurrath, and Y. Ozoe, "Structure-activity relationships of seco-prezizaane and picrotoxane/picrodendrane terpenoids by Quasar receptor-surface modeling," Bioorganic and Medicinal Chemistry, vol. 12, no. 15, pp. 4159-4167, 2004.

[114] R. Waliwitiya, P. Belton, R. A. Nicholson, and C. A. Lowenberger, "Effects of the essential oil constituent thymol and other neuroactive chemicals on flight motor activity and wing beat frequency in the blowfly Phaenicia sericata," Pest Management Science, vol. 66, no. 3, pp. 277-289, 2010.

[115] C. M. Priestley, E. M. Williamson, K. A. Wafford, and D. B. Sattelle, "Thymol, a constituent of thyme essential oil, is a positive allosteric modulator of human $\mathrm{GABA}_{\mathrm{A}}$ receptors and a homooligomeric GABA receptor from Drosophila melanogaster," British Journal of Pharmacology, vol. 140, no. 8, pp. 1363-1372, 2003.

[116] E. E. Enan, "Molecular response of Drosophila melanogaster tyramine receptor cascade to plant essential oils," Insect Biochemistry and Molecular Biology, vol. 35, no. 4, pp. 309-321, 2005.

[117] D. L. Kerns and S. D. Stewart, "Sublethal effects of insecticides on the intrinsic rate of increase of cotton aphid," Entomologia Experimentalis et Applicata, vol. 94, no. 1, pp. 41-49, 2000.

[118] T. G. Amos, P. Williams, P. B. Du Guesclin, and M. Schwarz, "Compounds related to juvenile hormone: activity of selected terpenoids on Tribolium castaneum and T. confusum," Journal of Economic Entomology, vol. 67, no. 4, pp. 474-476, 1974.

[119] D. C. Stamopoulos, P. Damos, and G. Karagianidou, "Bioactivity of five monoterpenoid vapours to Tribolium confusum (du Val) (Coleoptera: Tenebrionidae)," Journal of Stored Products Research, vol. 43, no. 4, pp. 571-577, 2007. 
[120] D. P. Papachristos and D. C. Stamopoulos, "Fumigant toxicity of three essential oils on the eggs of Acanthoscelides obtectus (Say) (Coleoptera: Bruchidae)," Journal of Stored Products Research, vol. 40, no. 5, pp. 517-525, 2004.

[121] B. Z. Sahaf and S. Moharramipour, "Fumigant toxicity of Carum copticum and Vitex pseudo-negundo essential oils against eggs, larvae and adults of Callosobruchus maculatus," Journal of Pest Science, vol. 81, no. 4, pp. 213-220, 2008.

[122] A. A. Işikber, N. Özder, and Ö. Sağlam, "Susceptibility of eggs of Tribolium confusum, Ephestia kuehniella and Plodia interpunctella to four essential oil vapors," Phytoparasitica, vol. 37, no. 3, pp. 231-239, 2009.

[123] A. K. Tripathi, V. Prajapati, A. Ahmad, K. K. Aggarwal, and S. P. S. Khanuja, "Piperitenone oxide as toxic, repellent, and reproduction retardant toward malarial vector Anopheles stephensi (Diptera: Anophelinae)," Journal of Medical Entomology, vol. 41, no. 4, pp. 691-698, 2004.

[124] D. P. Papachristos and D. C. Stamopoulos, "Sublethal effects of three essential oils on the development, longevity and fecundity of Acanthoscelides obtectus (Say) (Coleoptera: Bruchidae)," Hellenic Plant Protection Journal, vol. 2, no. 2, pp. 91-99, 2009.

[125] K. Voda, B. Boh, and M. Vrtačnik, "A quantitative structureantifungal activity relationship study of oxygenated aromatic essential oil compounds using data structuring and PLS regression analysis," Journal of Molecular Modeling, vol. 10, no. 1, pp. 76-84, 2004.

[126] C. Hansch, R. Garg, A. Kurup, and S. B. Mekapati, "Allosteric interactions and QSAR: on the role of ligand hydrophobicity," Bioorganic and Medicinal Chemistry, vol. 11, no. 9, pp. 20752084, 2003.

[127] M. Leyva, J. E. Tacoronte, and M. D. C. Marquetti, "Chemical composition and lethal effect of essential oil from Pimenta racemosa (Myrtales: Myrtaceae) on Blatella germanica (Dictyoptera: Blattellidae)," Revista Cubana de Medicina Tropical, vol. 59, pp. 154-158, 2011.

[128] M. B. Isman, S. Miresmailli, and C. MacHial, "Commercial opportunities for pesticides based on plant essential oils in agriculture, industry and consumer products," Phytochemistry Reviews, vol. 10, no. 2, pp. 197-204, 2011.

[129] J. N. Seiber, J. Coats, S. O. Duke, and A. D. Gross, "Biopesticides: state of the art and future opportunities," Journal of Agricultural and Food Chemistry, vol. 62, no. 48, pp. 11613-11619, 2014. 

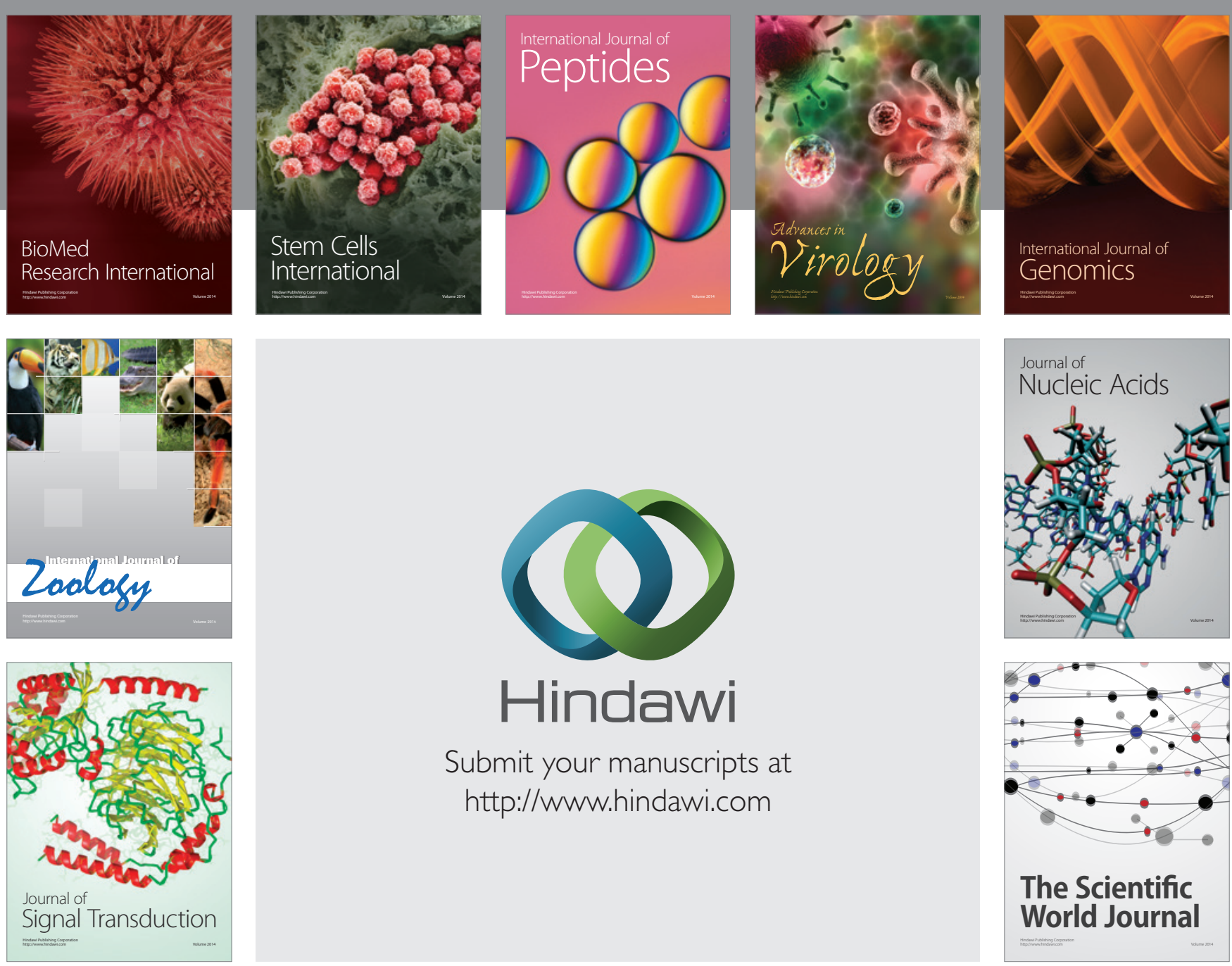

Submit your manuscripts at

http://www.hindawi.com
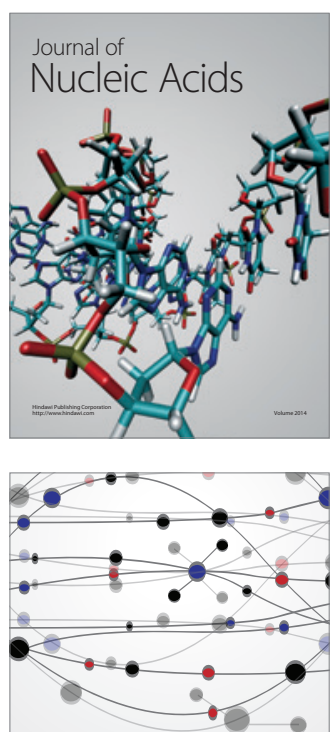

The Scientific World Journal
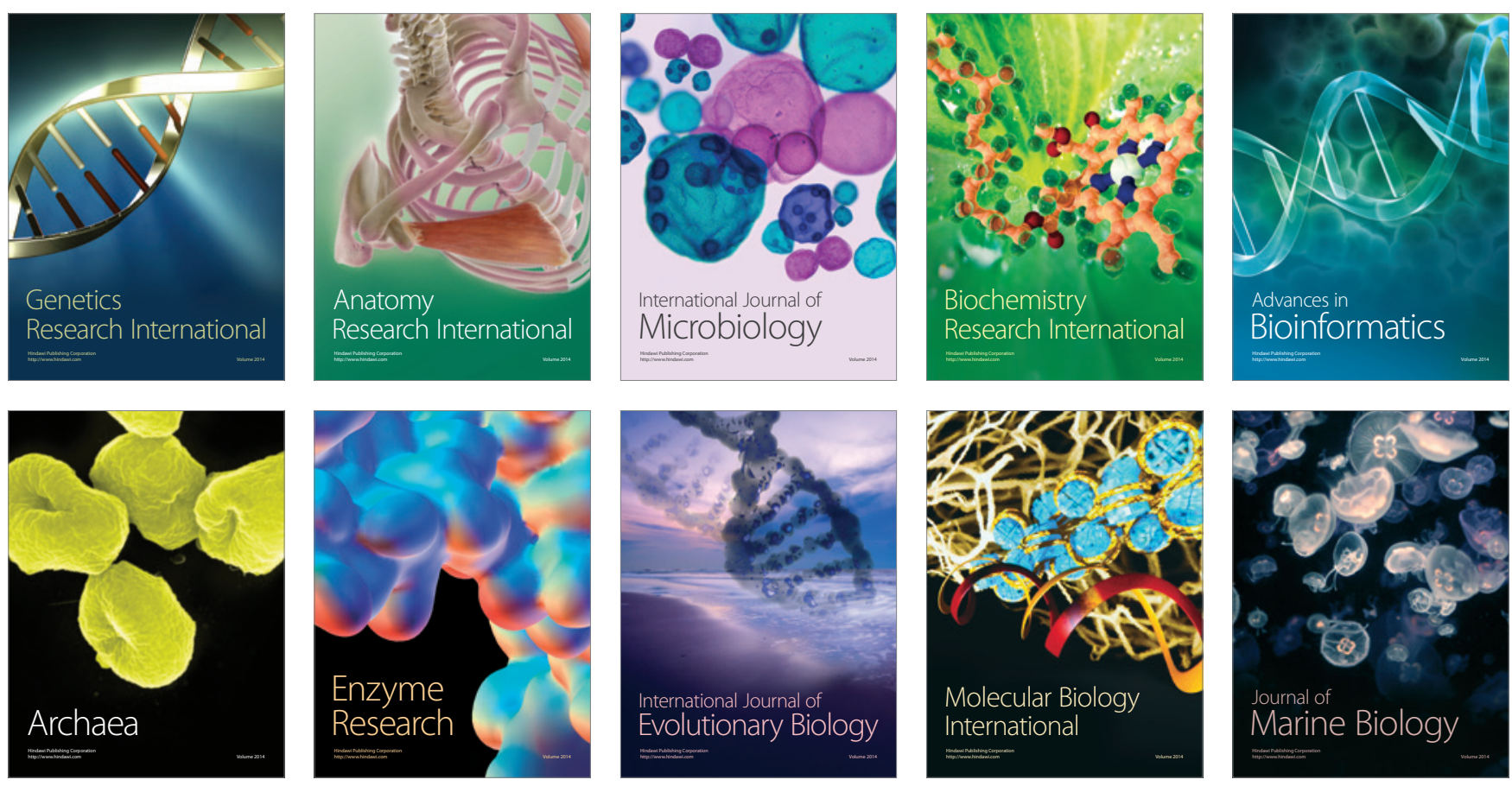